\title{
Homeostatic regulation of the endoneurial microenvironment during development, aging and in response to trauma, disease and toxic insult
}

\author{
Andrew P. Mizisin • Ananda Weerasuriya
}

Received: 24 September 2010/Revised: 15 November 2010/ Accepted: 16 November 2010/Published online: 7 December 2010

(C) The Author(s) 2010. This article is published with open access at Springerlink.com

\begin{abstract}
The endoneurial microenvironment, delimited by the endothelium of endoneurial vessels and a multilayered ensheathing perineurium, is a specialized milieu intérieur within which axons, associated Schwann cells and other resident cells of peripheral nerves function. The endothelium and perineurium restricts as well as regulates exchange of material between the endoneurial microenvironment and the surrounding extracellular space and thus is more appropriately described as a blood-nerve interface (BNI) rather than a blood-nerve barrier (BNB). Input to and output from the endoneurial microenvironment occurs via blood-nerve exchange and convective endoneurial fluid flow driven by a proximo-distal hydrostatic pressure gradient. The independent regulation of the endothelial and perineurial components of the BNI during development, aging and in response to trauma is consistent with homeostatic regulation of the endoneurial microenvironment. Pathophysiological alterations of the endoneurium in experimental allergic neuritis (EAN), and diabetic and lead neuropathy are considered to be perturbations of endoneurial homeostasis. The interactions of Schwann cells, axons, macrophages, and mast cells via cell-cell and cellmatrix signaling regulate the permeability of this interface. A greater knowledge of the dynamic nature of tight junctions and the factors that induce and/or modulate these key elements of the BNI will increase our understanding of
\end{abstract}

\footnotetext{
A. P. Mizisin $(\square)$

Department of Pathology 0612, School of Medicine,

University of California, San Diego, 9500 Gilman Drive,

La Jolla, CA 92093-0612, USA

e-mail: amizisin@ucsd.edu

A. Weerasuriya

Division of Basic Medical Sciences,

Mercer University School of Medicine, Macon, GA, USA
}

peripheral nerve disorders as well as stimulate the development of therapeutic strategies to treat these disorders.

Keywords Blood-nerve barrier · Blood-nerve interface . Capillary $\cdot$ Endoneurial fluid ·

Endoneurial hydrostatic pressure - Endothelium .

Nerve microenvironment · Perineurium .

Peripheral neuropathy

\section{Introduction}

Vertebrate axons, their associated Schwann cells and other resident cells of peripheral nerves function within a specialized milieu intérieur - the endoneurial microenvironment. Exchange of material between this intrafascicular physiological space and general extracellular space is restricted and regulated by the blood-nerve barrier (BNB), also known as the blood-nerve interface (BNI), which consists of endoneurial vascular endothelium and a multi-layered ensheathment, the perineurium. The relative impermeability of the BNI to blood-borne material protects the endoneurial microenvironment from potentially harmful plasma constituents and rapid fluctuations of plasma solute concentrations, which could adversely affect Schwann cell and axonal functions. The absence of lymphatic drainage in the endoneurial space further emphasizes the protective nature of the BNI, because, apart from the cerebral microenvironment, this is the only other physiological space known to lack lymphatic drainage [169]. The composition of the endoneurial fluid and its physical properties are regulated by homeostatic mechanisms located at the BNI and in the endoneurial cellular elements, a concept that was first proposed about 30 years ago [194, 195]. 
Early morphological studies with several tracers described the permeability of the BNI as either leaky or impermeant [110], thus downplaying the graded permeability of this interface to solutes of different sizes demonstrated by subsequent physiological studies [for review see 108, 186]. In fact, increases in endoneurial vessel permeability occur without any accompanying ultrastructural evidence of endothelial cell damage or death [99, 184], and physiological studies have measured initial increases and subsequent decreases in endoneurial vessel and perineurial permeability [191]. Taken together, these observations do not support a simple passive restrictive barrier impeding access of hydrophilic solutes to the endoneurial microenvironment, but rather the operation of endoneurial homeostatic mechanisms, much as in the blood-tissue interfaces of other organs. Thus, for reasons outlined above and in anticipation of the increasing significance of emerging concepts, such as the neurovascular unit and immunological driven dynamic permeability changes, it is proposed that the "interface" in BNI represents the regulatory and dynamic blood-nerve exchange of various solutes and water much better than the "barrier" in BNB. In an attempt to support this proposal, this review will first consider the structural components of the BNI and the biophysical properties of the endoneurial microenvironment before examining key variables during development, aging, trauma, and finally select diseases and toxic insults to emphasize the relevance of considering pathophysiological alterations as perturbations of endoneurial homeostasis.

\section{Blood-nerve interface}

The endoneurial microenvironment of the peripheral nervous system extends from the proximal root attachment zones of cranial and spinal nerves to the distal sensory and motor end organs. The BNI defines this microenvironment and consists of connective tissue and vascular components, which exhibit some regional variation along the peripheral neuraxis. The perineurium, which is the connective tissue ensheathment of nerve fascicles, separates general extracellular space from intrafascicular, endoneurial space, while the endothelial lining of endoneurial microvessels, which are derived from the anastomosing plexuses of the vasa nervorum that travel within and through the perineurium, separates vascular space from endoneurial space.

\section{Spinal roots}

At the subarachnoid angle, the meninges of the central nervous system (CNS) merge with the connective tissues ensheathing peripheral nerves (Fig. 1) [41]. Here the dura mater blends with the epineurium, while the arachnoid layer merges with the outer lamellae of the perineurium [41, 152]. The inner layers of the perineurium derive from the sheath surrounding the nerve roots. Reminiscent of the pia mater [42], the outer root sheath contains loosely arranged cell layers with intermittent junctional contacts, allowing communication between the subarachnoid and intercellular spaces [41]. The squamous cells of the inner root sheath layers are closely opposed [152], with a surrounding basal lamina that is continuous only in the cells in contact with the endoneurium [41].

Spinal roots traverse the subarachnoid space from the root attachment zone to the subarachnoid angle (Fig. 1). The inner root sheath begins as an open-ended tube in the vicinity of the root attachment zone and merges peripherally with the inner portion of the perineurium at the subarachnoid angle [42]. In the root attachment zone, continuity between the subarachnoid space containing cerebral spinal fluid (CSF) and the endoneurium of the roots via pial tissue space has been demonstrated ultrastructurally (Fig. 1) [42] and represents a pressure-driven egress pathway for CSF, which is a source of endoneurial fluid. The structural basis for the interface between parenchyma of the CNS and peripheral nervous system (PNS) is the glia limitans, which is composed of astrocytic foot processes that cross each rootlet at its point of attachment to the spinal cord [for review see 31]. Channels containing either individual myelinated fibers or groups of unmyelinated axons perforate these astrocytic foot processes. The interpenetration of CNS and PNS tissues in the rootlets or spinal cord surface forms transition zones with a length of rootlet containing both tissues [31]. In the transition zone central to the glia limitans, myelinated fibers are ensheathed by oligodendrocytes, while peripheral to it, myelinated and unmyelinated fibers are ensheathed by Schwann cells. The abrupt change in glial ensheathment at the glia limitans is in marked contrast to the continuity of myelinated and unmyelinated axons that cross this surfacelimiting membrane.

The vasculature of spinal roots consists of large, sparsely distributed vessels, comparable to those observed in spinal cord white matter as well as the more distal portions of the peripheral neuraxis [11]. In line with the greater metabolic demands of nerve-cell-body-containing nervous tissue [108], capillary density is greater in sensory ganglia and spinal cord gray matter [11]. Blood flow in the spinal cord white matter and roots is about half that measured in spinal cord gray matter and sensory ganglia [143, 144, 170, 205], reflecting these regional differences in capillary density. Because of fenestrations in endothelial cells as well as open interendothelial clefts [109], vessels in spinal roots are permeable to morphological tracers of various molecular weights [108]. 


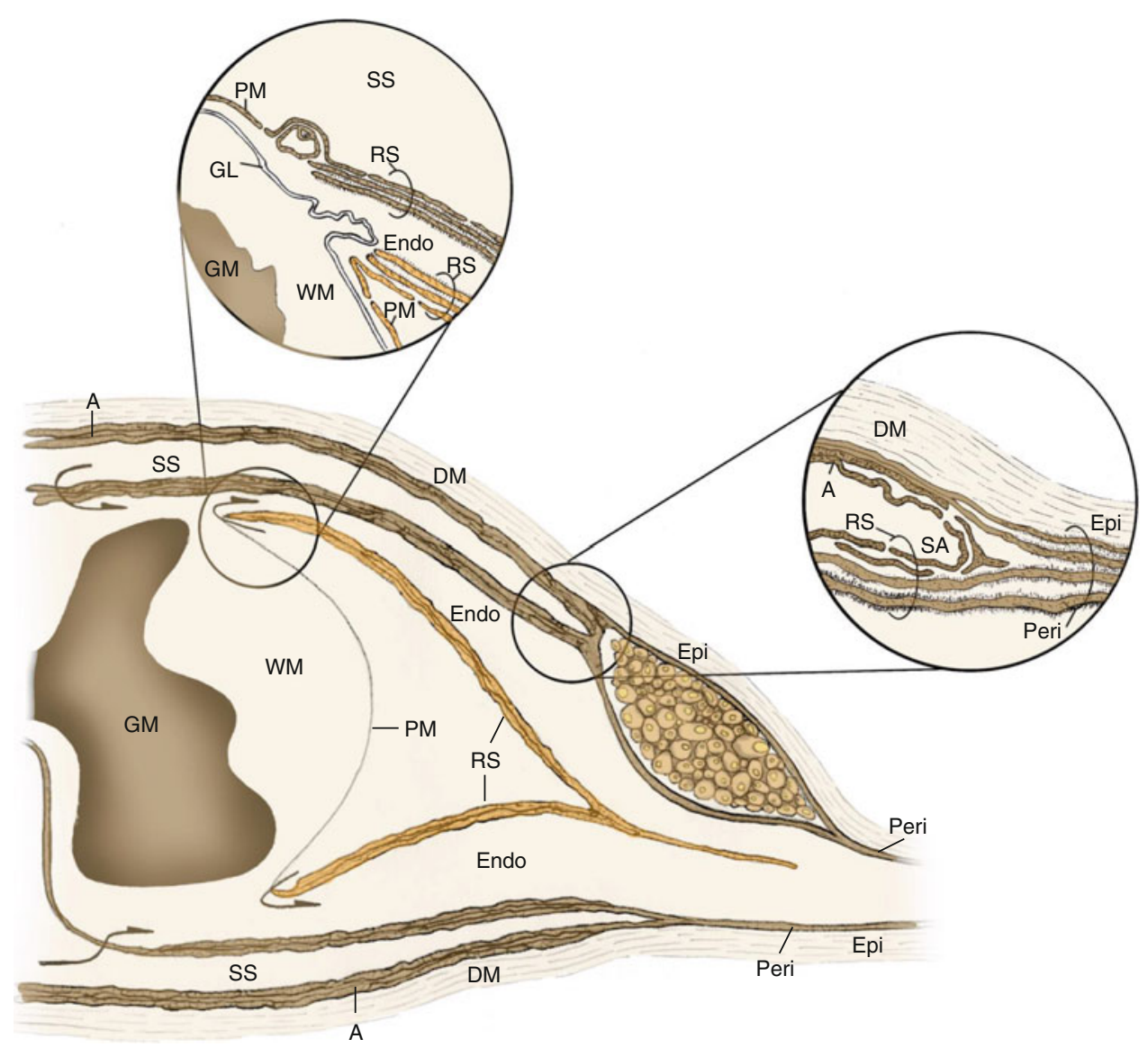

Fig. 1 Relationship of the meningeal coverings of the spinal cord to spinal root and peripheral nerve connective tissue ensheathments. The outermost meningeal covering, the dura mater $(D M)$, is continuous with the outermost connective tissue of peripheral nerve, the epineurium (Epi), while the arachnoid layer $(A)$ merges with the outer perineurial lamellae at the subarachnoid angle $(S A)$. The inner layers of the perineurium (Peri) derive from the inner layers of the root sheath $(R S)$. Inset at upper right shows high-power view of the transition of connective tissues at the subarachnoid angle. As the dorsal and ventral spinal roots pass through subarachnoid space (SS), some of the arachnoid layer is reflected onto the root sheath at the subarachnoid angle, becoming the outermost layers of this connective

\section{DRG and other ganglia}

A connective tissue capsule continuous with the epi-perineurial ensheathment of peripheral nerves surrounds sensory and autonomic ganglia. The perineurial cellular lamellae of ganglia are bounded by basal laminae on both sides and have numerous tight junctions and desmosomes, as well as occasional gap junctions [6, 108]. Interposed between the cellular layers are collagen-containing extracellular spaces. The 2-4 cellular lamellae of the perineurium of the superior cervical ganglion act as a diffusion barrier, with the innermost layers preventing transperineurial movement of larger molecular weight tracers [6]. In contrast to the perineurium and the endoneurial vessels of the distal nerve trunk, the endoneurial tissue ensheathment. At the root attachment zone of dorsal and ventral roots, the pia mater $(P M)$ of the spinal cord is reflected onto the spinal root and merges with the outer layers of the root sheath, while the glia limitans $(G L)$ continues across the attachment zone to form the interface between the central and peripheral nervous systems. The innermost layers of the root sheath terminate on the spinal root side of the glia limitans. At the root attachment zones, continuity between the subarachnoid space and the endoneurium (Endo) has been demonstrated ultrastructurally (arrows). Inset at upper left illustrates a highpower view of the dorsal root attachment zone, associated spinal cord white matter $(W M)$ and underlying gray matter $(G M)$. Modified from $[42,69]$

vasculature of cranial, spinal, and autonomic ganglia is permeable to a variety of low- and high-molecular weight tracers $[6,45]$. As in the spinal roots, blood-borne tracer is extravasated through vessels with fenestrated endothelia and open inter-endothelial clefts within minutes of injection [6].

\section{Peripheral nerves}

As noted above, the epineurium and perineurium comprise the connective tissue ensheathment of nerve trunks. The epineurium surrounds mono-fascicular nerves or loosely binds fascicles of multi-fascicular nerves together. Epineurial vasculature is an anastomosing plexus fed by radicular vessels that connect to the extrinsic component of 


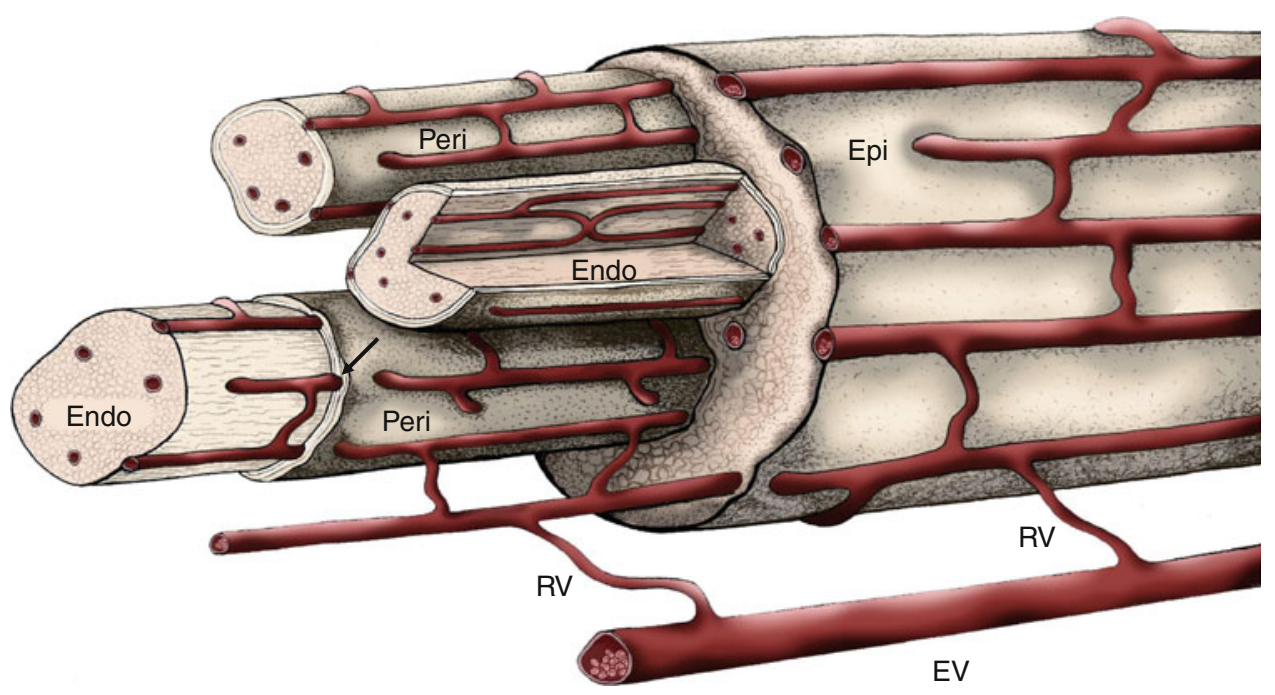

Fig. 2 Vasa nervorum. The microcirculation of peripheral nerve derives from regional extrinsic vessels $(E V)$ off of which branch radicular vessels $(R V)$ that supply the intrinsic circulation of the vasa nervorum. The intrinsic circulation consists of longitudinally oriented vessels that course through epineurium (Epi), descend to the perineurium (Peri) and ultimately join with vessels in the endoneurium (Endo) via transperineurial connections (arrow). Extensive anastomotic connections are present at all levels of the intrinsic circulation. Modified from [76]

junctions are occasionally observed linking cells in adjacent layers together (Fig. 3b) [19]. Tight junctions, particularly those of the innermost perineurial sleeves, provide a barrier to the diffusion of various large molecular weight tracers, as well as restrict diffusion of low molecular weight tracers [110, 162].

Anastomotic connections between the epineurial and the perineurial circulation occur at various levels in the perineurium, with the longitudinally oriented vessels obliquely penetrating the cellular layers to connect with endoneurial vessels (Figs. 2, 3a) [95]. Single perineurial layers accompany penetrating vessels entering the endoneurium and represent focal continuities between the epineurial and the endoneurial spaces [19]. Edema-induced increases in endoneurial hydrostatic pressure (EHP) leave obliquely penetrating perineurial vessels vulnerable to compression [95]. The endoneurial and transperineurial vessels comprise a sparsely distributed network of arterioles, capillaries, and venules that remains intact when an individual fascicle is isolated [76]. As might be expected, nerve blood flow is comparable to that measured in spinal cord white matter and roots, which is about half that of flow in spinal cord gray matter and sensory ganglia [143, $149,170,205]$. The diameters of the continuous, nonfenestrated capillaries are larger than those of capillaries in adjacent skeletal muscle (6-10 vs. 3-6 $\mu \mathrm{m})$ [11]. In contrast to leaky endoneurial vessels in new-borne mouse sciatic nerve, tight interendothelial junctions in adult endoneurial vessels represent the structural basis for restricted permeability to vascular tracers of various molecular weights [61, 105, 106, 109], while occasional 


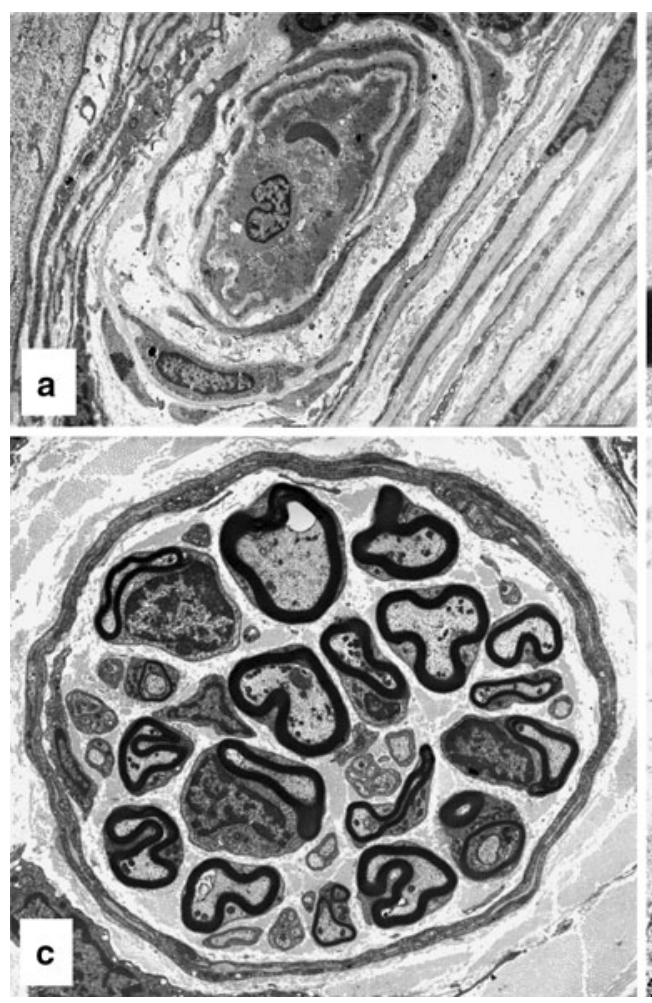

Fig. 3 Perineurial ensheathment of peripheral nerve. a A transperineurial vessel in a sural nerve biopsy from diabetic patient has penetrated the outer perineurial lamellae on its way from the epineurium (left) to the endoneurium (right). b Common peroneal nerve biopsy from a diabetic cat showing a portion of fascicle with four perineurial lamellae. Arrow indicates junctional contact between the inner two concentric perineurial cell layers. c Dermal nerve in

open interendothelial gaps differentiate these vessels from the consistently tight vessels in most regions of the brain [11].

Sensory and motor end organs

As nerve fascicles become smaller and approach sensory and motor end organs, the number of concentric perineurial layers decreases (Fig. 3c). Whether individual myelinated or unmyelinated fibers are surrounded by perineurium as they reach sensory and motor end organs has been a controversial subject and seems to be dependent on the particular end organ. Some maintain that a complete perineurial investment is continuous with the capsules of sensory organs, such as Meissner, Krause, and Pacinian corpuscles, and also covers the motor endplate $[152,153]$. Others have provided ultrastructural evidence that the perineurial layer ends just before reaching the motor endplate, providing an open-ended termination with continuity between epineurial and endoneurial space [19]. While ultrastructural evidence is lacking, there is likely an open-ended perineurial sleeve for simple sensory nerve formations and arborizations ending in connective tissue, as well as the naked nerve endings of intra-

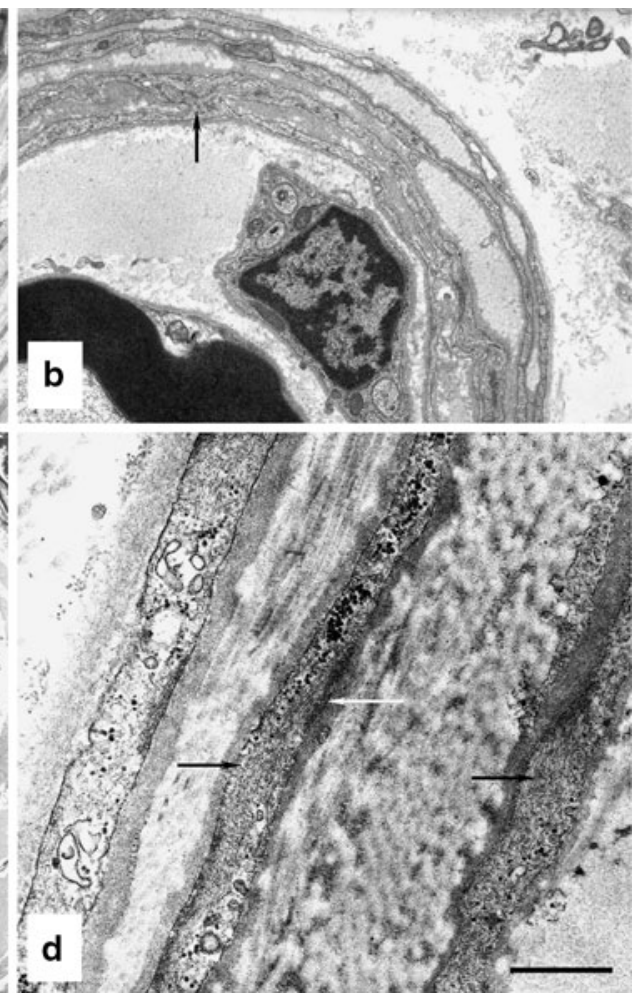

glabrous skin of rat hind paw ensheathed by a perineurium with only two lamellae. d Perineurium in a common peroneal nerve biopsy from a diabetic cat. Note filaments (black arrows) and dense bodies (white arrow), which are attributes of contractile cells. Bar $6.36 \mu \mathrm{m}$ in (a), $0.69 \mu \mathrm{m}$ in (b) $2.00 \mu \mathrm{m}$ in (c) and $0.27 \mu \mathrm{m}$ in (d). Electron micrograph in a kindly provided by HC Powell

epidermal innervation, and glomus and Merkel complexes [80, 152]. Open-ended perineurial sleeves provide distal continuity of the endoneurial microenvironment with the surrounding extracellular tissue space and may ensure maintenance of proximo-distal endoneurial fluid flow by providing distal drainage sites (see below).

\section{Nerve microenvironment}

Myelinated and unmyelinated nerve fibers are the major constituent of the endoneurium, a uniquely regulated microenvironment that, unlike most extracellular tissue spaces, lacks a lymphatic circulation and is under positive hydrostatic pressure. Blood-nerve exchange and convective endoneurial fluid flow, which is driven by a proximodistal hydrostatic gradient, are the major sources of input to and output from the endoneurium. Because homeostatic mechanisms regulate this internal space, pathophysiological alterations of the nerve microenvironment can be viewed as the consequence of altered endoneurial homeostasis. 
Fig. 4 Cellular constituents of the endoneurial microenvironment in peripheral nerve. A small nerve fascicle ensheathed by perineurium (Peri) surrounded by epineurial collagen fibrils is shown with myelinated $(M F)$ and unmyelinated $(U M F)$ fibers, a single endoneurial vessel $(V)$ and scattered fibroblasts $(F)$ embedded in the loose connective tissue of the endoneurium. Not shown are pericytes, resident macrophages and masts cells. Modified from [76]

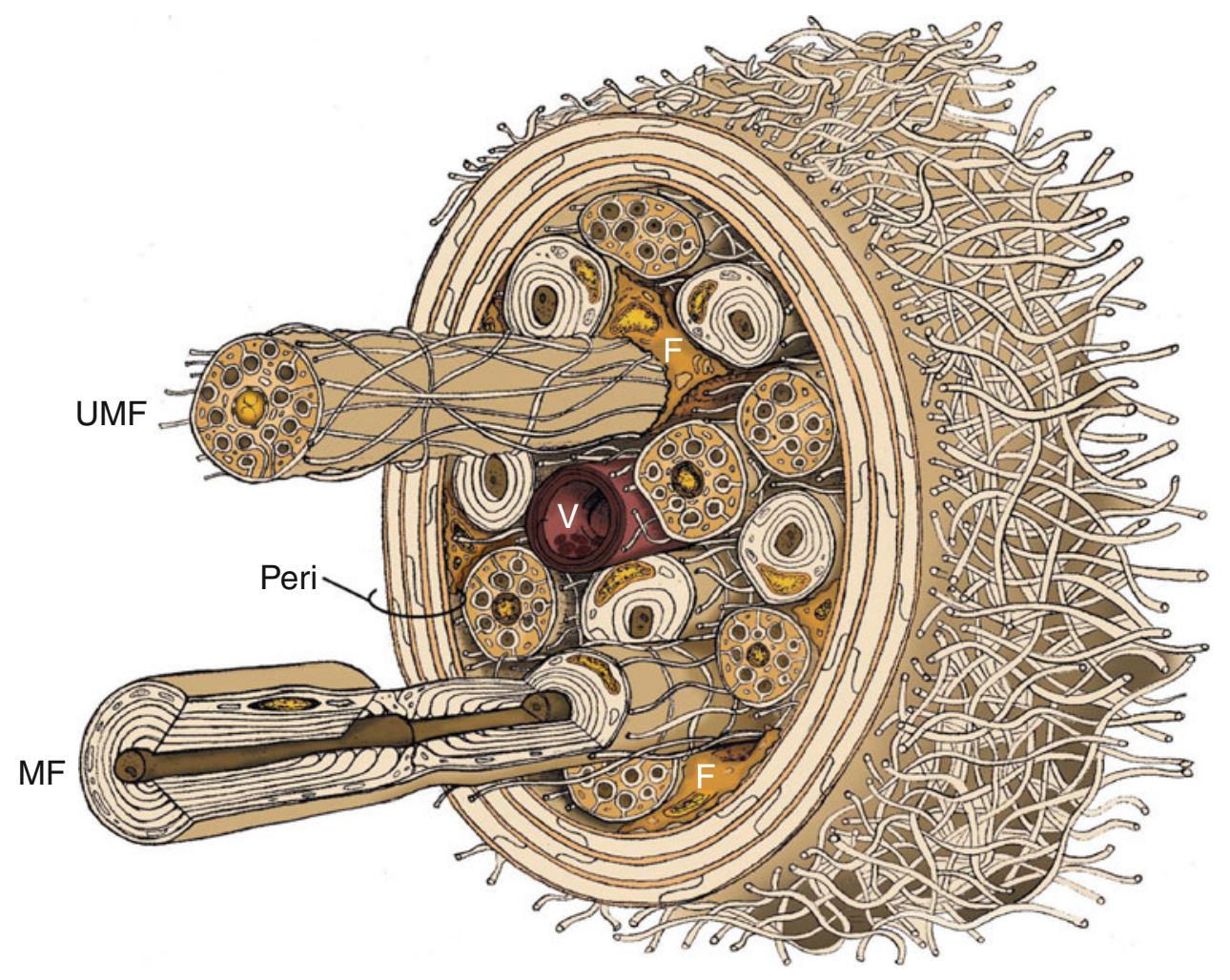

\section{Endoneurium}

The BNI defines a specialized microenvironment designed to support myelinated and unmyelinated fibers carrying sensory afferent input to and motor efferent output from the spinal cord and brain (Fig. 4). In rats, these fibers occupy about $75 \%$ of the endoneurial area of sciatic or tibial nerves [30, 88, 131]. Though more numerous, the smaller unmyelinated fibers inhabit only a small fraction (approximately $4 \%$ ) of the total endoneurial space occupied by nerve fibers [88]. Schwann-cell-derived basal or external laminae surround all myelinated and unmyelinated fibers, which are embedded in a network of collagen fibrils within a proteoglycan-containing ground substance. The extracellular space of the nerve microenvironment occupies about $20-25 \%$ of endoneurial area, with collagen fibrils taking up twice as much area as "structureless" extracellular space, which presumably reflects the space filled by ground substance $[8,88]$. Nerve fibers, fibroblasts, and other cells are nourished by an intrinsic vasculature (Fig. 2) that occupies just $1 \%$ of endoneurial area [88], which, in rat sciatic nerve, equates to an approximate density of 68 blood vessels $/ \mathrm{mm}^{2}$ [20]. While present in the epineurium, the endoneurium lacks a lymphatic circulation [169]. With a few important exceptions that may be a consequence of the absence of lymphatic capillaries, entry into and exit from the nerve microenvironment is tightly regulated.
Early workers observed that surgically breaching the perineurium resulted in the immediate herniation of underlying nerve fibers [168] that, over time, underwent focal demyelination and remyelination [163]. The herniation of endoneurial contents through a perineurial window highlights several important characteristics of the nerve microenvironment. Unlike other extracellular connective tissue spaces, the perineurium-contained endoneurium is under positive pressure. Subsequent studies have established that normal EHP in peripheral nerves is in the range of $2-3 \mathrm{mmHg}[72-74,87,97-100]$ and that the compliance of the perineurium is greater when responding to small increases in endoneurial volume than when faced with large increases [70]. Thus, the nerve microenvironment accommodates small increases in endoneurial volume without a corresponding increase in EHP, a consequence of the buffer provided by a compliant perineurium.

\section{Endoneurial fluid}

The endoneurial water content of the sciatic nerve of adult rats is about $70 \%[53,84,184,191]$, with water distributed between the intracellular and extracellular compartments. As noted, the extracellular space within a nerve fascicle is about $20-25 \%$ of the total endoneurial volume and water in this compartment is either free or part of the hydrated gellike ground substance. In rats, the electrolyte content of 
endoneurial fluid has been assessed by performing energy dispersive spectrometry on picoliter samples obtained after making a small perineurial window [85, 87, 90-92]. Although subsequent studies report electrolyte levels that are more isotonic to their serum counterparts $[85,87,90$, 91], initial studies [92] suggested that endoneurial fluid sodium, chloride, and potassium were hypertonic to serum levels of these electrolytes, as reported in a much earlier study employing different analysis methods [63]. Using an elution procedure and subsequent immunoblotting, endoneurial fluid was determined to have $3.6 \%$ of total endoneurial protein, with albumin the dominant protein [120]. However, plasma levels of albumin, which is produced in the liver [116], are higher than those in endoneurial fluid, in line with albumin's role as a major determinant of vascular oncotic pressure.

In terms of fluid dynamics, the endoneurial contents consist of a non-compressible aqueous solution and a somewhat compressible cellular content constrained by a compliant perineurial sheath. Hence, the volume of the endoneurial contents and the compliance of the perineurium determine EHP. Fluid flow to and from the endoneurium occurs across the walls of the endoneurial vasculature and by convective proximo-distal endoneurial fluid flow (see below). Fluid does not normally enter the endoneurium across the perineurium, given the slight positive EHP. Thus, endoneurial fluid exchanges material with blood directly across the endoneurial vascular endothelium and, in some instances, indirectly across the multilayered perineurium, while being turned over by convective proximo-distal endoneurial fluid flow.

Under typical conditions, electrolyte content of aspirated endoneurial fluid is, for the most part, iso-osmotic with serum concentrations of sodium, chloride, and potassium ions [87, 88, 90, 91] and not likely to exert an interstitial osmotic pressure. In contrast, endoneurial albumin can be calculated to exert an interstitial oncotic pressure of about $3 \mathrm{mmHg}$ [65]. The normal EHP of 2-3 mmHg will oppose endoneurial oncotic pressure and thus minimize net fluid filtration from the endoneurial vasculature. However, this balance of oncotic and hydrostatic forces can be disturbed if the capillary permeability to albumin increases slightly, allowing the endoneurial albumin concentration to rise and thus draw more fluid from the vascular compartment into the endoneurial interstitium. The resulting endoneurial edema together with the low compliance and hydraulic conductivity of the perineurium will elevate EHP. Net fluid gain by the endoneurial space will cease when a new equilibrium is established among the hydrostatic and oncotic pressures of the endoneurial and vascular compartments. It is quite likely that this is the mechanism of edema formation observed in experimental diabetic and lead neuropathy, as well as early Wallerian degeneration (see below). On the other hand, the edema present in galactose-induced neuropathy is not vasogenic but due to the presence of an excess of endoneurial fluid electrolytes [87, 90, 91, 187].

\section{Routes of blood-nerve exchange}

Both direct and indirect routes are available for exchange of material across the BNI. The direct pathway is across the endothelium separating endoneurial vascular space from the endoneurium. The indirect route requires a movement from epineurial vascular space through the relatively leaky epineurial capillaries into extracellular space and then across the perineurium into the endoneurium. The following observations implicate the direct pathway as the major route of blood-nerve exchange. Endoneurial capillaries are permeable to lanthanum, while the perineurium is impermeable to this ionic tracer $[6,77,153]$. Histamine increases the permeability of endoneurial capillaries but not the perineurium to macromolecular tracers [135, 164]. Intravascular perfusion with a hyperkalemic solution inactivates peripheral nerve much more rapidly than bathing nerve with the same solution [62]. Endoneurial capillaries are two orders of magnitude more permeable to radiolabeled albumin than the perineurium $[164,185,188,193-195$; Weerasuriya, unpublished observations]. In spite of about a fourfold increase in perineurial permeability during Wallerian degeneration, the $\mathrm{PS}_{\mathrm{A}}$ (permeability coefficient surface area product) of the frog sciatic nerve decreases by more than $60 \%$, reflecting the greater sensitivity of $\mathrm{PS}_{\mathrm{A}}$ to capillary permeability [184]. In leprosy, endoneurial blood vessels become permeable to ferritin, whereas the perineurium remains impermeable [13]. Strictly speaking, BNI permeability to a given solute is slightly higher than the endoneurial capillary permeability to that same solute, with the difference due to the minor contribution of the relatively impermeable perineurium.

On the basis of the permeability measurements to hydrophilic solutes of various sizes and before the availability of adequate structural evidence, physiologists postulated that the capillary endothelium contained both small and large hydrophilic pores [39, 112]. The ratio of small to large pores, though variable, seems to be in the range of about 30,000:1 [51, 138]. Recent evidence suggests that the structural basis of small pores are the interendothelial clefts [56], which have a width of about $20 \mathrm{~nm}$ and occupy about $0.4 \%$ of the capillary surface area [17]. Because of their rarity, the identity of large pores is less certain. Potential candidates are transendothelial channels formed by the fusion of plasmalemmal invaginations, shuttling by pinocytotic vesicles, widened endothelial intercellular junctions and/or fenestrae [139]. Pinocytotic uptake of horseradish peroxidase and the appearance of this 
tracer in phagosomes of perivascular macrophages have been observed in normal rats and mice [47, 158, 159], supporting transendothelial movement of large molecules. Properties of the small- and large-pore pathways are exhaustively reviewed elsewhere [22, 140, 171]. In contrast to endothelia, perineurial cells do not display an apicobasal polarity. Thus, the major route for transperineurial passage of material is a paracellular pathway, regulated by belts of intercellular tight junctions that are arranged in series when the perineurium is multilayered. A recent report of the presence of VE-cadherin in perineurial cells [161], as well as the presence of tight junction proteins, zonula occludens-1 (ZO-1), occludin and claudins (claudin-1 and -3 in the perineurium and claudin-5 in the endothelium), in both perineurial and endoneurial endothelial cells $[134,175]$ is consistent with similar mechanisms regulating permeability at these sites (see below).

\section{BNI transporters, enzymes and receptors}

Given the relative impermeability of the BNI, it is not surprising that exchange of several solutes depends on the presence of specific pumps, transporters, enzymes and receptors designed to meet the metabolic, ionic and other requirements of nerve [for review see 5]. The endoneurial microenvironment, unlike the cerebral microenvironment, does not require a moment-to-moment regulation of nutrients and oxygen. The earlier radioisotopic demonstration of facilitated transport of D-glucose [137], have been complemented by reports on the presence of GLUT1 in both endothelial cells and perineurial cells [32, 33, 79]. In keeping with the earlier postulate that the perineurium is a specialized connective tissue, the above studies did not demonstrate an apicobasal polarity of GLUT-1 transporters in perineurial cells, suggesting that the role of perineurial GLUT-1 transporters is the nourishment of these ensheathing cells. In nerve, $\mathrm{Na}^{+}, \mathrm{K}^{+}$ATPase is present in both luminal and abluminal plasma membranes of endothelial cells as well as the innermost perineurial cells $[113,125]$, with no apparent polarity at either site, which is in contrast to the predominately abluminal expression in brain endothelial cells [12] and implies that maintenance of the ionic microenvironment of nerve is less critical than that in brain [5]. Alkaline phosphatase, which is found on both the luminal and abluminal surfaces of brain endothelial cells, is absent from perineurial cells but is found on endoneurial endothelial cells, where it transports phosphate ions and esters, and hydrolyzes phosphorylated metabolites [83, 176]. The L-type amino acid transporter (LAT-1), which preferentially transport neutral amino acids, the creatine transporter, which moves the creatine necessary for storage of high-energy phosphate groups, as well as the monocarboxylate acid transporter (MCT-1), which transports monocarboxylates such as lactate, have been demonstrated in nerve and brain endothelia in vitro and/or in vivo [57, 104, 148]. More recently, LAT-1, creatine transporter and MCT-1 were detected in primary endoneurial endothelial cell cultures [204]. The transferrin receptor (OX-26 antigen), which the transports ferric ions required as co-factors supporting oxidative and other metabolism, is present in only trace amounts in endothelial cells and perineurium [111]. An important efflux transporter of toxins and xenobiotics, $\mathrm{p}$-gp or multidrug resistance gene 1a, has also been demonstrated in the BNI [147]. While expression of GLUT-1, alkaline phosphatase, and OX-26 antigen in the brain endothelia is astrocyte-dependent, it is unclear what factors regulate expression of these and other key molecules in the BNI, although Schwann cell signaling via desert hedgehog has recently been implicated in the development of the perineurium [113] and more recently in the induction and maintenance of the BNI [154]. Moreover, recent in vitro experiments suggest that pericytes modify BNI function and junctional molecules through secretion of a variety of soluble factors [156].

\section{Proximo-distal endoneurial fluid flow}

In addition to the blood-nerve exchange discussed above, another putative source of input to and output from the endoneurium is convective endoneurial fluid flow. The presence of a proximo-distal flow of fluid was first demonstrated in rat and guinea pig sciatic nerve, using endoneurial injections of dyes, crystals, and radioactive mineral salts as indices of fluid movement and with conclusions based on the comparisons of proximo-distal spread of indicators in dead and living tissue [197]. The use of relatively large $(100 \mu \mathrm{L})$ injection volumes and small hydrophilic tracers that could have migrated down the nerve by entering the vascular compartment and later reentering the endoneurial space precluded the calculation of a precise rate of convective fluid flow, but suggested an approximate rate of $3 \mathrm{~mm}$ per hour, similar to results obtained studying traumatized chicken sciatic nerves [82]. Using another approach, convective fluid flow was calculated to be $4-8 \mathrm{~mm}$ per hour by injecting $10 \mu \mathrm{L}$ of tetrodotoxin into the endoneurium and monitoring the rate and spread of inactivation [71]. More recent experiments using intraneural microinjections of ${ }^{22} \mathrm{Na}$ show a distribution pattern of this radiotracer along the length of the nerve at three different survival times that is consistent with a progressive proximo-distal movement of the isotope (Weerasuriya, unpublished observations). 
With respect to the driving force of proximo-distal fluid flow, descriptive studies on EHP [126] are consistent with CSF pressure in the spinal cord being the pressure head for the proximo-distal flow of endoneurial fluid. Hydrostatic pressure is about $10 \mathrm{mmHg}$ in spinal cord, about $3-5 \mathrm{mmHg}$ in dorsal root ganglia, and about $2-3 \mathrm{mmHg}$ in peripheral nerves [100]. The presence of this pressure gradient from the interstitial spaces of the spinal cord to the endoneurial interstitium of peripheral nerves, as well as the continuity between the spinal subarachnoid space and the endoneurial space at the root attachment zone (Fig. 1) [41, 81], supports the contention that CSF pressure is the main propulsive force of the endoneurial fluid. However, this contention is not without theoretical limitations. For example, the fate of CSF pressure-driven endoneurial fluid at the distal ends of sensory nerves lacking open perineurial sleeves is not clear [69]. One possibility is that the perineurium in such nerves is more permeable distally than proximally to allow for a transperineurial dissipation of endoneurial fluid. If not, then one has to postulate a slower turnover of endoneurial fluid at the distal end of some sensory nerves lacking open perineurial sleeves, which could account for the greater vulnerability sensory nerves to pyridoxine toxicity [60].

\section{Endoneurial fluid turnover}

The albumin content of desheathed human sural nerve is $8.7 \mu \mathrm{g} / \mathrm{mg}^{-1}$ of dry weight [118]. Assuming the endoneurial wet/dry weight ratio is 3.0, endoneurial albumin is extracellular and free, and endoneurial extracellular space is $25 \%$, the albumin content per nerve dry weight can be converted to an albumin concentration of $11.6 \mathrm{mg} / \mathrm{mL}^{-1}$ in endoneurial fluid. Based on this endoneurial fluid albumin concentration, a plasma albumin concentration of $33.1 \mathrm{mg} / \mathrm{mL}^{-1}$ [118] and the $\mathrm{PS}_{\mathrm{A}}$ to albumin [189], the calculated rate of blood-nerve albumin transfer is about $1.2 \mathrm{mg} / \mathrm{g}^{-1} / \mathrm{day}^{-1}$. At this rate of transfer, and assuming relatively constant albumin concentrations in endoneurium and plasma, about $30 \%$ of the endoneurial albumin is turned over each day. By comparison, CSF and its constituents are turned over about 3-4 times each day [55].

The rate of albumin removal from the endoneurium is comparable to the rate of blood-nerve albumin transfer calculated above. In non-neural tissues, lymphatic drainage plays a role in clearing interstitial albumin, while CSF and perivascular drainage are sinks for extracellular albumin in the CNS [135]. In peripheral nerve, in the absence of both lymphatics and an active CSF circulation, the route of removal of albumin and other macromolecules remains to be identified. The metabolic breakdown of albumin to supply amino acids to axons and glia is one possibility.
Another possibility is the proximo-distal convective flow of endoneurial fluid discussed above.

\section{Endoneurial homeostasis}

In order to maintain the constancy of the milieu intérieur, multicellular organisms employ complex homeostatic mechanisms directed at stabilizing different regulated variables. Highly specialized and protected extracellular microenvironments are maintained via interfaces with vascular and extracellular spaces that are essential for the compartmentalization of specialized milieux intérieurs. A nerve fascicle, the cylindrical, perineurial-delimited structural entity encompassing axons, glial cells and other attendant satellite cells (Fig. 4), is the relevant physiological functional unit for the peripheral nervous system. The specialized microenvironment of peripheral nerve fibers is maintained by regulated blood-nerve exchange across the BNI and turnover of endoneurial fluid by convective fluid flow, which is vital for the maintenance of endoneurial physiological parameters including blood flow, $\mathrm{O}_{2}$ tension, $\mathrm{pH}$, oncotic pressure, hydrostatic pressure, and ion concentrations. Some of these physiological parameters have been measured: $\mathrm{PS}_{\mathrm{A}}$ to $\left[{ }^{14} \mathrm{C}\right]$ sucrose $[138,150],\left[{ }^{14} \mathrm{C}\right]$ glucose [137] [ ${ }^{125} \mathrm{I}$ ] albumin [188], and ${ }^{22} \mathrm{Na},{ }^{42} \mathrm{~K}$ and ${ }^{36} \mathrm{Cl}$ [182, 184, 187]; endoneurial blood flow [75, 94, 96, 144]; EHP [74, 97]; and ion concentration in endoneurial fluid [71, 85, 87, 90, 91, 92, 187, 189]. Other parameters have been described only qualitatively or not at all: endoneurial concentration of $\mathrm{H}^{+}$and $\mathrm{Ca}^{2+}$; rate of convective endoneurial fluid flow; volume of endoneurial extracellular space; perineurial permeability to macromolecules; and tortuosity of the endoneurial extracellular contents. The above list is neither exhaustive nor does it relate to all the pathophysiological alterations associated with the endoneurial microenvironment. Nevertheless, changes in parameters, such as endoneurial water content, EHP and the $\mathrm{PS}_{\mathrm{A}}$ of various solutes, reflect osmotic imbalances that can be monitored for evidence supporting homeostatic regulation of the nerve microenvironment. Thus, it is hoped that discussion of these few variables in the context of development and aging, recovery from nerve trauma, and the responses to disease and toxic insults will support the notion that developmental or pathophysiological changes of the nerve microenvironment elicit endoneurial homeostatic responses.

\section{Development and aging}

During normal development, the nerve microenvironment of juvenile animals is more exposed to macromolecules of 


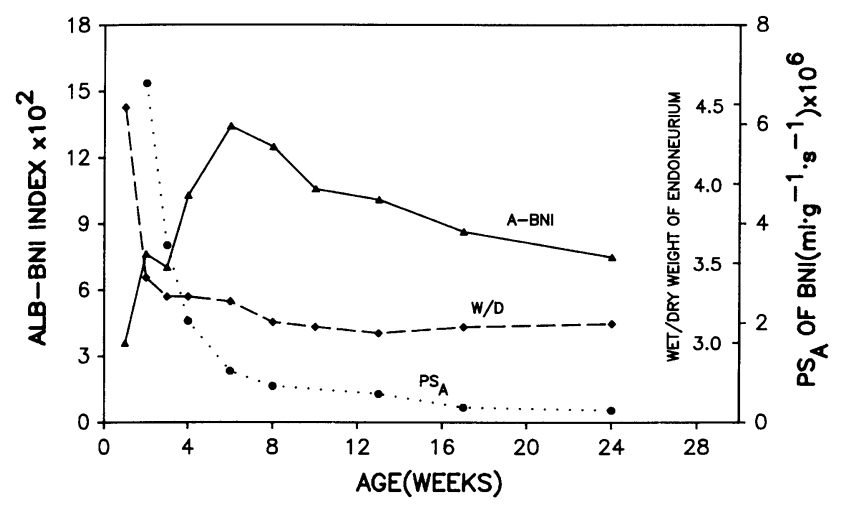

Fig. 5 Developmental changes in BNI. Temporal correlation between $\mathrm{PS}_{\mathrm{A}}$ and ${ }^{125}$ albumin, BNI index to albumin and endoneurial wet weight/dry weight ratio of rat sciatic nerve during development. Reproduced with permission [189]

vascular origin than that of adult animals, as shown qualitatively in studies employing morphological tracers [61, 160] and quantitatively in studies assessing the $\mathrm{PS}_{\mathrm{A}}$ of the BNI [184]. Both perineurial [61] and endoneurial vascular [160] components of the BNI of juvenile rodents are permeable to Evan's blue albumin or HRP until about 2 weeks after birth. During the first weeks after birth, quantitative studies with radiolabeled albumin show a precipitous decline in $\mathrm{PS}_{\mathrm{A}}$ and endoneurial water content that reaches adult values by about 8 weeks after birth, indicating that endoneurial capillaries and the perineurium become less permeable during development (Fig. 5) [184]. Interestingly, the BNI index to albumin, a measure of endoneurial albumin, increases until about the 6 weeks after birth, after which it declines until adult values are attained 13 weeks after birth. The increase in the endoneurial albumin possibly reflects an initial gradual reduction in both perineurial clearance of albumin and its use as a metabolic substrate after the peak of myelination, while the combination of the developmental decrease in microvessel permeability and continued metabolic clearance would gradually reduce endoneurial albumin to levels found in adult nerve.

An intriguing issue arising out of these observations is how developing nerve with its highly permeable BNI avoids the pathology observed in an adult nerve with a comparably permeable BNI. In the adult, extravasation of plasma proteins inevitably leads to endoneurial edema and increased EHP, resulting primarily from albumin-induced elevation of oncotic pressure in the endoneurial interstitial space. Due to the operation of Starling forces, water drawn into the endoneurial interstitium from the vascular compartment leads to increased endoneurial water content and, together with low perineurial compliance and hydraulic conductivity, causes an elevation in EHP, which can occlude the obliquely penetrating transperineurial vessels that feed the endoneurial microcirculation [95].
By contrast, a highly permeable BNI during initial development does not lead to edema and elevated EHP because a more permeable perineurium prevents the endoneurial accumulation of fluids and osmolytes, allowing for the clearance of this material by epineurial lymphatic vessels. In addition, a higher compliance of the juvenile endoneurial tissue mass would also buffer a tendency for EHP elevations. Thus, the need for greater blood-nerve exchange of material to support the active metabolism associated with growth, as well as tight junction dissolution and reformation during vasculogenesis-induced endothelial proliferation, likely promote a more permeable endoneurial microvasculature in developing nerve.

At the other end of the developmental spectrum, the nerve microenvironment and BNI integrity have been studied in aged rats [178]. The $\mathrm{PS}_{\mathrm{A}}$ to sucrose in the sciatic nerve, as well as vascular space and water content of tibial nerve were assessed in rats at 3,11 , and 31 months of age. No age-dependent differences were observed in any of these variables, suggesting that, once established in early adulthood, the integrity of the BNI is not altered even in senescent rats. However, aging is associated with increased EHP, which has been shown to have two developmental plateaus, one from about 3 to 13 weeks of age, and a second from 6 months onward [23]. The first increase in EHP is associated with the establishment of BNI integrity in young adult animals, while the second may be associated with the age-associated reductions in perineurial compliance [23]. Thickening of the basal laminae of perineurial cells has been observed in biopsies from diabetic patients as well as older control subjects and may be a structural correlate of reduced compliance of the ensheathing perineurium [59].

\section{Trauma}

After a nerve is transected, crushed or otherwise injured, myelinated and unmyelinated fibers undergo a process called Wallerian degeneration distal to the site of injury [24, 142, 166, 174]. Axons and myelin sheaths collapse, myelin is degraded and Schwann cells dedifferentiate and proliferate $[14,114,167]$ before, if conditions permit, axons regenerate and, as they contact Schwann cells, initiate remyelination [3, 49, 119]. The fact that perineurial permeability increases only about twofold during Wallerian degeneration [191, 196] argues against a 'breakdown' of this component of the BNI. Although lipid droplets and proteinaceous material are present in the perineurium of degenerating nerves, perineurial cells show no evidence of disruption [66, 198], rather they proliferate, hypertrophy and increase their organelle content [66]. Thus, an alternative and more plausible interpretation is that the bimodal 


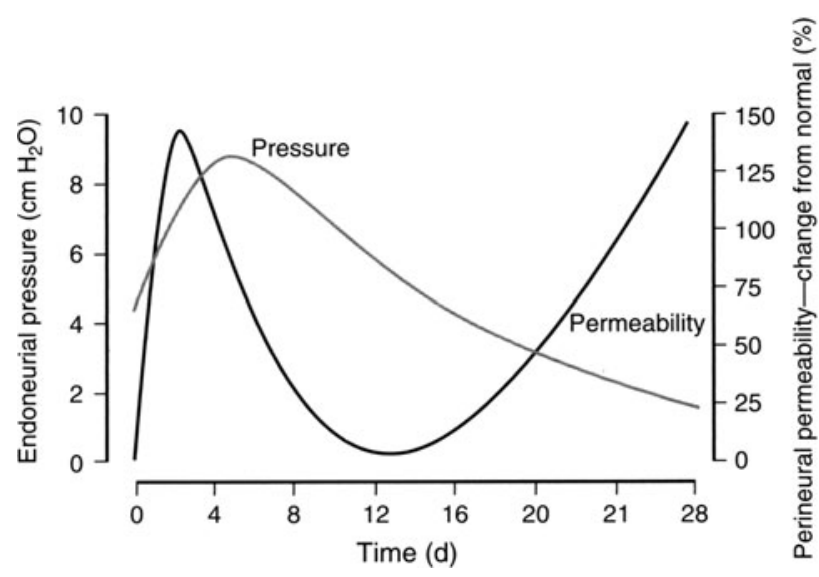

Fig. 6 Endoneurial hydrostatic pressure and perineurial permeability during Wallerian degeneration. BNI $\mathrm{PS}_{\mathrm{A}}$ to ${ }^{22} \mathrm{Na}$ during the first 4 weeks of Wallerian degeneration is shown. Reproduced with permission [191]

increase in perineurial permeability (Fig. 6) is part of a dynamic endoneurial homeostatic response.

Lasting only a few days, the initial peak of perineurial permeability [191], is most likely related to an acute inflammatory response triggered by the trauma of nerve section, as well as the proliferative response of the perineurium [66]. In addition to decreased expression of intercellular junctional proteins, such as claudin-1 and -5 , occluding, VE-cadherin and connexin43 [44], transected or crushed degenerating nerves show an increased number of degranulating mast cells [27, 66, 126, 198], which release histamine, a biogenic amine with potent inflammatory properties known to promote vascular permeability [128], as well as fenestrated endoneurial endothelium, which could contribute to the development of the extracellular endoneurial exudates [102]. The peak of EHP occurs after the initial peak of perineurial permeability, which is consistent with an increase in vascular permeability coincident with a decline in perineurial permeability, leading to an accumulation of endoneurial osmolytes of vascular origin. The later sustained increase of perineurial permeability and hydraulic conductivity may be a component of endoneurial homeostasis related to dissipating EHP by transperineurial movement of endoneurial fluid and clearing myelin debris from the endoneurium (Fig. 6). Increased permeability of both the perineurial and vascular components of the BNI facilitates the entry of the macrophage precursors, monocytes, into the endoneurium $[102,167]$.

Unlike nerve transection, crush injury preserves the external laminae surrounding individual myelinated and unmyelinated fibers, expediting functional recovery because regenerating axons are more likely to re-establish contact with their original sensory and motor end organs.
Thus, the examination of the BNI during nerve regeneration provides an opportunity to determine whether the osmotic imbalances associated with the Wallerian degeneration resolve in a manner consistent with a homeostatic regulatory response [185]. Although re-expression of intercellular junctional proteins is completed within days after crush injury [44], the BNI $\mathrm{PS}_{\mathrm{A}}$ to ${ }^{22} \mathrm{Na}$ is increased from the 4th day up to the 8th week after a crush lesion, allowing easier access of water into the endoneurial compartment. However, by the 18th week after nerve crush, the $\mathrm{PS}_{\mathrm{A}}$ to ${ }^{22} \mathrm{Na}$ returns to normal but endoneurial water content, which increases from day 4 , remains elevated, with its peak during the 2 nd week after crush corresponding to the period of increased permeability of the BNI to ${ }^{22} \mathrm{Na}$. While an increased BNI PS $\mathrm{A}_{\mathrm{A}}$ to plasma macromolecules would elevate the osmolality of endoneurial fluid and draw water into the endoneurial microenvironment, a decrease in the endoneurial fluid turnover could also contribute to the increased water content of the regenerated nerve. Morphological evidence of nerve edema and increased EHP are coincident after crush injury [129] but endoneurial water content can still be elevated after EHP of regenerating nerve returns to normal [192]. Increased perineurial compliance of regenerated nerve may help maintain EHP in the normal range in spite of increased endoneurial water content.

Physical nerve injuries induced by cold and heat also result in Wallerian degeneration and subsequent regeneration but with interesting time-course differences compared to nerve crush or transection. In nerve crush, EHP peaks 6 days after injury and returns to normal over the next 30 days [129], while lesions induced by a surgical cryoprobe produce two peaks of EHP [98]. Within 90 min of injury, EHP reaches the highest values yet recorded $(17 \mathrm{mmHg}$ ) and subsides within 1 day, followed by second peak that occurs after 6 days and is comparable in height and duration to what is observed in nerve crush injury. The initial marked increase in EHP after $90 \mathrm{~min}$ is associated with severe vascular injury resulting in extravasation of blood into the endoneurium. Large volumes of endoneurial fluid resulting from vascular injury are thought to stretch the perineurium through its elastic range, producing a large increase in EHP, which then subsides as a consequence of an acceleration of proximo-distal flow or because the compliance or hydraulic conductivity properties of the perineurium are altered [98]. Focal heat injury induced by a carbon dioxide laser appears intermediate between crush and cryoprobe injury, with an initial high EHP within 2 days that persists during the process of Wallerian degeneration [93]. In this study, the ability to focus the laser nerve injury to only a part of a fascicle moderated the consequences, which otherwise would be expected to be comparable to that observed after a cryogenic nerve lesion. 


\section{Disease}

\section{EAN}

Experimental allergic neuritis (EAN), an established model of Guillain-Barre syndrome (GBS), has been induced by direct inoculation of crude nerve homogenates [64, 180, 202] or neuritogenic peptides [132], as well as by adoptive transfer of $\mathrm{T}$ cell lines sensitized to minimum length neuritgenic peptides [131]. In the animal model and human disease, the primary lesion is demyelination $[7,10,15,29$, $40,64,202]$, resulting from immune-mediated targeting of myelin proteins. Nerve edema occurs prior to the peak of demyelination [133] and is associated with increased EHP and inflammation (Fig. 7) [131]. The severity and time course of this immune-mediated endoneurial osmotic imbalance is dependent on the method used to induce EAN [132]. Adoptive transfer of $\mathrm{T}$ cells sensitized to neuritogenic peptides produces a peak in edema, EHP and inflammatory infiltrate 7 days after inoculation that ultimately resolves to near-normal levels by 11 days. The endoneurial osmotic imbalance occurs earlier and is more
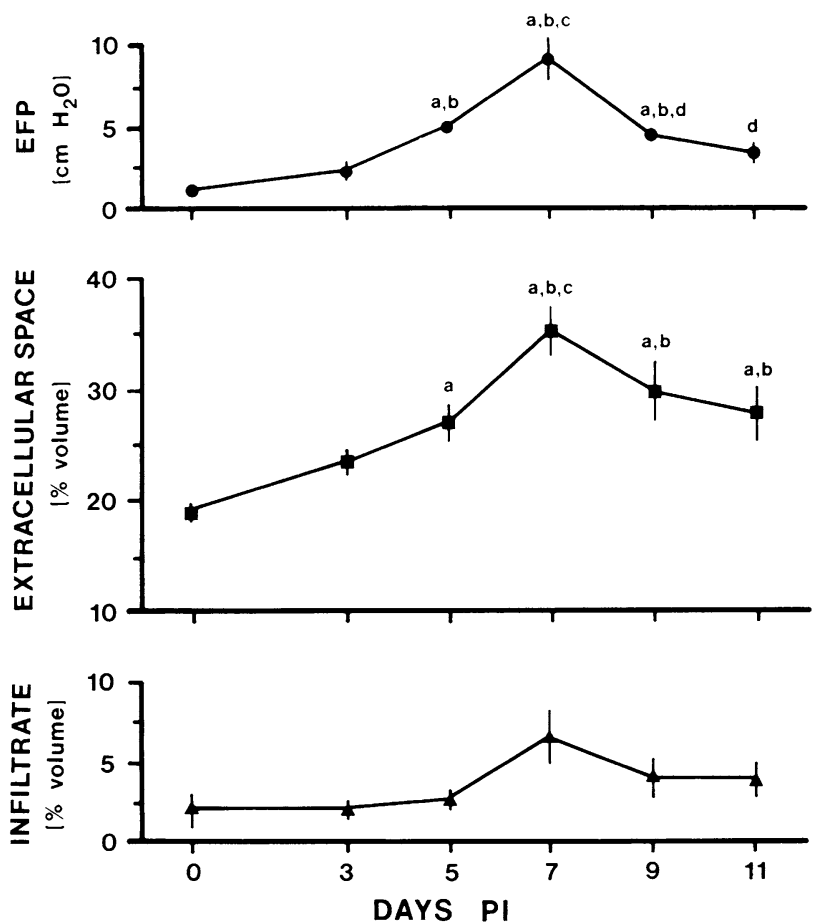

Fig. 7 Endoneurial fluid pressure and morphometric estimates of endoneurial extracellular space and inflammatory infiltrates in Lewis rats as a function of time after injection with $\mathrm{P}_{2}$-sensitized $\mathrm{T}$ cell lines or $\mathrm{T}$ cells from rats with adjuvant arthritis (0 days). Note that these parameters all peak at 7 days. Data are presented as mean \pm SD and were analyzed with ANOVA after which multiple comparisons were made with the Fisher PLSD test: $a P<0.05$ versus 0 days; $b P<0.05$ versus 3 days; $c P<0.05$ versus 5 days; and $d P<0.05$ versus 7 days. Reproduced with permission [131] severe after adoptive transfer of $\mathrm{T}$ cells sensitized to neuritogenic peptides than after direct sensitization with these peptides, a reflection of using $\mathrm{T}$ cells already sensitized to these antigens [131, 132].

The onset of nerve edema in EAN is coincident with a dramatic change in the BNI. The venular endothelium adopts a rhomboid appearance reminiscent of high endothelial venules that is markedly different from their normal scaphoid morphology (Fig. 8a-c) [131]. Having transiently lost tight junctions, some endothelial cells are separated with deep clefts between them, presumably in response to infiltrating leukocytes that leave the subendothelial basal lamina fragmented at these sites (Fig. 8c). Within the endoneurium, mononuclear cells of perivascular infiltrates can sometimes be seen adhering to the surface of mast cells, whose degranulation augments the increase in vascular permeability to macromolecules promoted by interendothelial separation [123]. Proteinaceous electrondense material, fibrin and inflammatory cells are also found in the subperineurial space and clumps of fibrin have been observed between perineurial lamellae, indicative of a change in perineurial permeability to macromolecules. These observations suggest that the endoneurial osmotic imbalance in EAN is a result of extravasation of plasma accompanying leukocyte infiltration and consequent secretions of pro-inflammatory mediators by infiltrating leukocytes, activated Schwann cells, resident macrophages and mast cells that precedes and precipitates immunemediated demyelination. The transient loss and re-establishment of endothelial tight junctions, the decline of edema and EHP, and, perhaps most importantly, resolution of physical signs of neurological impairment indicates that this process is self-limiting in EAN [131] and may reflect an adaptive endoneurial homeostatic response to peripheral nerve inflammation. However, in chronic human inflammatory conditions, such as chronic inflammatory demyelinating polyradiculoneuropathy and Crow-Fukase or POEMS syndrome, derangements of the BNI reflected by altered patterns of claudin- 5 and $\mathrm{ZO}-1$ immunostaining [54] and endoneurial immunoglobulin staining [146] may not be as readily self-limiting.

Although demyelination is the pathognomonic lesion in EAN and GBS, axonal injury has been a persistent observation in both the animal model and human disease [7, 10, 15, 29, 40, 64, 202]. The temporal association of axonal degeneration with edema and increased EHP at a time when demyelinated fibers are scarce implies that the axon is vulnerable to the inflammatory process and consequent endoneurial osmotic imbalance [131]. While the role of anti-ganglioside antibody- and complement-mediated damage, particularly in axonal variants of animal models and GBS, is well established as a mechanism of axonal injury [for review see 199], a compressive effect of nerve 
Fig. 8 Tibial nerve endoneurial microvessels in EAN resulting from injection of $\mathrm{P}_{2}$-sensitized $\mathrm{T}$ cell lines or $\mathrm{T}$ cells from rats with adjuvant arthritis. Vessel from control rat injected with $\mathrm{T}$ cells sensitized to adjuvant arthritis (a) or from a rat where EAN was induced by injection of $\mathrm{P}_{2}$-sensitized T cells (b) and (c). Upper inset in $\mathbf{a}$ is from control rat and lower inset from a rat with EAN. Arrows indicate interendothelial clefts, which have tight junctions in (a) and are open in (c). Note fragmented endothelial basal lamina in (c) below arrow. Bar $100 \mu \mathrm{m}$ in insets, $1.43 \mu \mathrm{m}$ in (a), $2.00 \mu \mathrm{m}$ in (b) and (c). Reproduced with permission [131]

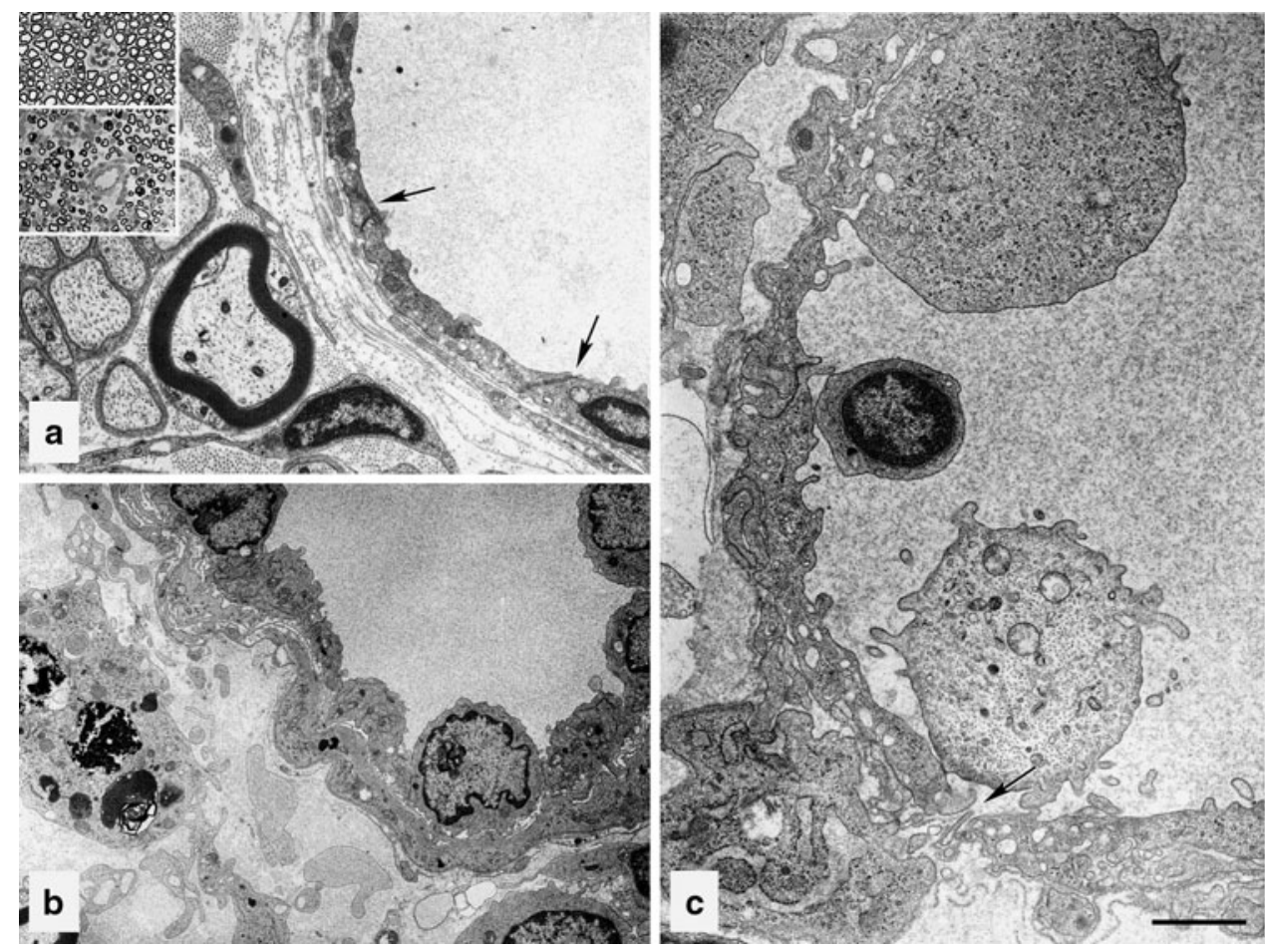

edema resulting in ischemia has been also been suggested [78]. It is worth noting that the nerve edema and increased EHP are associated with the reduced nerve blood flow and axonal damage in both hexachlorophene and galactose neuropathy [94, 96], and are believed to constrict transperineurial vessels by stretching the perineurium beyond its compliance limits $[52,95]$. The respiratory burst associated with macrophage-mediated demyelination in EAN and GBS [43] could exacerbate ischemia resulting from reductions in nerve blood flow. Compared to nerve crush or transection injuries, the limited extent of axonal injury in EAN would be expected to moderate the osmotic consequences of Wallerian degeneration discussed above.

\section{Diabetes}

Peripheral neuropathy is a chronic long-term complication of both insulin-dependent and insulin-independent diabetes mellitus that affects all cellular elements of nerve [89]. Demyelination can be primary or secondary to axonal degeneration, with both primary and secondary demyelination documented in the same nerve biopsy [145]. Segmental demyelination and axonal degeneration have been reported in various animal models, although the degree of coherence of structural nerve injury in human and experimental diabetic neuropathy depends on the model and the duration of diabetes. While not consistently observed, evidence of edema has been documented in both human and experimental diabetic neuropathy using a variety of techniques [36, 46, 53, 86, 87, 90, 91, 124], including noninvasive magnetic resonance spectroscopy [26, 37]. In some instances, increased EHP has been measured coincident with edema and increased endoneurial water content [73, 87]. These observations suggest that an endoneurial osmotic imbalance is a component of diabetesinduced nerve injury at some point in the development of neuropathy [26].

In an attempt to explore the etiology of nerve edema, the permeability of the BNI in diabetic neuropathy was initially investigated in qualitative studies using morphological tracers in various rodent models, including alloxan- and streptozotocin-diabetic rats, galactose intoxicated rats, BBWistar rats and $\mathrm{db} / \mathrm{db}$ mice. With one exception in alloxandiabetic rats [151], these studies demonstrated that the BNI of peripheral nerves was impermeable to tracers with molecular weights ranging from 12,000 to 70,000 and that the tight junctions of the endothelium and inner perineurial cell layers appeared intact [47, 124, 158, 159]. Subsequent measurement of increased endoneurial albumin as well as the demonstration of immunoreactants and other plasma proteins within sural nerves from patients with diabetic neuropathy [16, 35, 103] prompted a quantitative assessment in diabetic rats, which failed to document any diabetes-induced increases in the $\mathrm{BNI} \mathrm{PS}_{\mathrm{A}}$ to albumin [58]. However, when albumin was glycated either in vitro or derived from patients with diabetic neuropathy, its $\mathrm{PS}_{\mathrm{A}}$ was substantially increased, implicating diabetes-induced nonenzymatic glycosylation of proteins in the enhanced 
movement of plasma proteins across the BNI into the endoneurium [117]. Detection of horseradish peroxidase in endothelial pinocytotic vesicles and in phagosomes of perivascular macrophages [47, 158, 159] suggests that shuttling of pinocytotic vesicles may be involved in the movement of glycosylated plasma proteins across the BNI in diabetes mellitus. Accumulation of glycosylated plasma proteins and the osmotic consequences of Wallerian degeneration resulting from axonal injury after chronic neuropathy are likely to contribute to the endoneurial osmotic imbalance in diabetes.

Aspiration of picoliter amounts of endoneurial fluid and analysis of its electrolyte content identified the accumulation of endoneurial sodium and chloride ions as another source of potential osmolytes in experimental diabetes [87, $90,91]$. In galactose-fed and occasionally streptozotocindiabetic rats, nerve edema, increased EHP and endoneurial electrolyte accumulation are coincident and, interestingly, all of these parameters are dependent on hyperglycemiainduced flux through the polyol pathway [36, 73, 87, 90, 91], which has long been considered an early pathogenic event because of the potential for an osmotic imbalance of the nerve microenvironment. Inhibiting aldose reductase, the key enzyme of the polyol pathway that immunolocalizes to Schwann cells of myelinated fibers [50, 125], prevents hyperglycemia-induced nerve edema, electrolyte accumulation as well as increases in EHP and mast cell number [88, 90]. It is not clear how polyol pathway flux induces an endoneurial osmotic imbalance but it is important to note that the $\mathrm{PS}_{\mathrm{A}}$ to mannitol of the BNI is increased in the experimental diabetes [84, 136] and that inhibiting aldose reductase prevents this increase in permeability to small hydrophilic solutes [177]. Regardless of the osmolyte involved, the osmotic consequences are likely to be exacerbated by the diabetes-induced thickening of the perineurial basal or external laminae [51, 59], which may compromise the compliance of the perineurium and thus initially worsen the consequences of nerve edema. Over time in chronic diabetic neuropathy, extensive loss of myelinated and unmyelinated fibers might counter the hydrostatic consequences of an osmotic imbalance and reduced perineurial compliance, resulting in transient endoneurial edema [26].

\section{Toxic insult}

\section{Lead neuropathy}

In peripheral nerve, nuclear inclusion bodies in endothelial and Schwann cells, endoneurial edema, elevation of EHP, increased permeability of BNI and demyelination are the major consequences of lead intoxication, with inclusion bodies observed first followed by endoneurial edema [200]. While an increase in the permeability of endoneurial capillaries was suggested to be the primary pathological event that precipitated subsequent Schwann cell damage and segmental demyelination [72, 99], later studies indicated that accumulation of lead in the endoneurium and nerve edema precede qualitative changes in the permeability of endoneurial capillaries [130, 201]. In rats, the BNI index to albumin, a measure of the rate of albumin entry and removal from the endoneurium, starts to increase only after 6 weeks of lead intoxication, suggesting that the change in BNI permeability is caused by the direct toxic effect of lead on Schwann cells [101]. A subsequent study [190] demonstrated that the peak of endoneurial lead content precedes the appearance of nuclear inclusion bodies, demyelination and morphological evidence of edema, and occurs 2 weeks prior to a threefold increase in the $\mathrm{PS}_{\mathrm{A}}$ to albumin, further supporting the notion that changes in permeability are not a consequence of the cytopathological disruption of the BNI.

Schwann cell nuclei and myelin are thought to initially sequester lead as a protective mechanism to minimize cytosolic lead concentrations that is ultimately overwhelmed [34, 155]. The subsequent breakdown of myelin provides osmolytes that promotes an egress of water from the endoneurial vasculature leading to edema and, without an increase in perineurial permeability [190], elevated EHP $[72,99]$. The increase in the permeability of the BNI could be a consequence of endothelial damage, a Schwann cellinitiated mechanism to clear myelin debris from the endoneurium or both. In either case, since interendothelial leakage of horseradish peroxidase is not profuse [25, 130] and endothelial cell nuclear inclusions are not an expression of outright injury, it is suggested that the change in BNI permeability represents an adaptive response to aid in the clearing of myelin debris from the endoneurium, promote the remyelination that occurs in chronically leadintoxicated rats [130] and restore endoneurial homeostasis. An intriguing and unresolved clinical issue is that lead toxicity predominantly leads to an encephalopathy in children, whereas in adults the major manifestation is a neuropathy. A greater vulnerability of the juvenile cerebral neurovascular unit to lead is a likely but, as yet, unproven possibility.

\section{Coordinating homeostatic regulation}

With the exception of intracerebral vessels, endoneurial microvessels have the least permeable endothelium of any vasculature in the body, while the inner layers of the ensheathing perineurium are even less permeable. However, as noted above, the permeability characteristics of the BNI 
are not constant during development or in response to trauma, disease or toxic insult and, in some instances, there is evidence for the independent modulation of endothelial and perineurial permeability, suggesting a capacity for coordinated regulation of the nerve microenvironment. The components of the BNI expend considerable metabolic energy maintaining not only the junctional integrity of endothelial and perineurial cells but also the specific pumps, transporters, enzymes and receptors required for blood-nerve exchange of critical material needed by all cellular elements of the endoneurial microenvironment. Thus, the dynamically selective permeability properties of the BNI extract a considerable metabolic cost and are likely coordinated by soluble factors that induce as well as modulate the tight junctions, actin cytoskeleton and associated adaptor, scaffold and signaling molecules of endothelial and perineurial cells.

\section{Neurovascular unit in nerve}

In recent years, the neurovascular unit has emerged as an important concept, which emphasizes that the integrated function and dysfunction of the brain results from interactions between neurons, astrocytes, oligodendrocytes, microglia, pericytes, and endothelial cells [2, 67, 68]. Functional aspects of cell-cell and cell-matrix signaling within the neurovascular unit include hemodynamic neurovascular coupling, neurotransmitter dynamics, matrix interactions for cell survival signals and regulation of the blood-brain interface [68]. The concept of a neurovascular unit, albeit with some modification, is equally relevant for the BNI, as well as other blood-neural interfaces [21]. In peripheral nerve, candidates for cellular components of the neurovascular unit are constituents of the BNI, including pericytes, as well as Schwann cells, axons, macrophages, and mast cells (Fig. 4). Given the low vascular density in peripheral nerve, signaling molecules from Schwann cells and axons would have to diffuse through greater distances to reach endoneurial vessels than those from pericytes or perivascular macrophages and mast cells. Hence, some components of the neurovascular unit in nerve, compared to that in the brain, are likely to operate in a larger volume and thus respond more slowly to perturbations.

\section{Cellular control of BNI}

Although the details of cell-cell and cell-matrix signaling within the neurovascular unit of peripheral nerve are not known, several observations implicate signals from Schwann cells and axons in the maintenance of BNI integrity. The endothelium of transperineurial vessels, which is initially permeable to plasma macromolecules, acquires tight junctions when the vessels penetrate the innermost layers of the perineurium to enter the endoneurium [107]. Thus, the induction of tight junctions in the inner layers of the perineurium, as well as in the endothelium of transperineurial vessels as they pass through these lamellae, implicates one or more diffusible factors present within the endoneurium. Further support for diffusible endoneurial factors comes from experiments in which the extraction of intrafascicular contents resulted in the breakdown of the perineurium, which was re-established if nerve regeneration was allowed [173]. Schwann cells and/or axons could be the source of factors capable of inducing the synthesis of junctional proteins and/or modulating their permeability. In this regard, it is noteworthy that the Schwann cell-derived signaling molecule, desert hedgehog, controls the development of peripheral nerve sheaths in embryonic and neonatal nerves [48, 113]. Further, desert hedgehog has been shown to be necessary for the maintenance of the normal permeability properties of the BNI [154].

Chronically transected nerves provide a clue about the source of a diffusible factor(s) that maintains the nearnormal $\mathrm{PS}_{\mathrm{A}}$ of the endoneurial endothelium to small nonelectrolytes in an environment without axons [183]. The presence of endothelial tight junctions in transected nerves lacking regenerating axons [66] argues for the Schwann cell and against axons as the source of a regulatory factor for the maintenance of junctional contacts in the endoneurial vasculature. On the other hand, the increased permeability of the perineurium accompanying axonal degeneration [66, 179, 195] implicates axonally derived factors in maintaining the relatively tight barrier properties of the perineurium. Hence, it is likely that Schwann cells and axons contribute to regulating the baseline resting permeability of the two components of the BNI. An integral aspect of endoneurial homeostasis is the ability of the BNI to adaptively alter its permeability properties to meet the various needs of the nerve microenvironment, which are dictated by programmed and gradual changes associated with growth and maturation, as well as disturbances precipitated by trauma and disease.

In addition to Schwann cells and axons, adaptive alterations in permeability of the BNI can be initiated and effected through immune responses. Recent evidence strongly implicates the immune system as an active modulator of BNI permeability in a whole host of conditions ranging from trauma to metabolic neuropathies to vascular disorders [38, 121, 127, 203]. Thus, hematogenous elements interacting directly with the endoneurial vascular elements affect increases in capillary permeability. Interestingly, the perineurium appears to be unusually resistant to inflammatory mediators [1]. Thus, immunomodulation of BNI permeability appears to be limited to the vascular component of this interface. Recent in vitro studies using 
primary endoneurial endothelial cells [204] and pericytes [156] have the potential to further elucidate solute, macromolecule, microbial, virus, and leukocyte interactions with the BNI. The in vitro approach has already pointed to a possible role for pericytes in secreting soluble factors capable of affecting endothelial tight junctions by upregulating claudin-5 [156].

\section{Molecular mediators of permeability}

Since the demonstration of junctional complexes in the epithelia of a variety of glands and organs [28], tight junctions have been recognized as the structural correlate of the paracellular component of transepithelial resistance. Ultrastructurally, tight junctions are characterized by a fusion of adjacent cell membranes that obliterates the intercellular space and is often associated with a subjacent dense cytoplasmic plaque [28]. Freeze-fracture studies reveal tight junctions to consist of a variable number of anastomosing strands, with permeability dependent on the number and complexity of the strands, as well as the presence of aqueous channels within strands [122]. Thus, tight junctions act as gates, which regulate paracellular permeability of ions and other small solutes, and fences, which restrict the diffusion of apical and basolateral or luminal and abluminal membrane components. More recently, tight junctions have also been recognized as dynamic bi-directional signaling complexes, which direct adaptive alterations in permeability and regulate related gene expression [172].

Tight junctions and their subjacent cytoplasmic plaques contain a variety of transmembrane, adaptor, scaffolding and signaling proteins, as well as transcriptional and posttranscriptional regulators [9]. The tetraspan transmembrane proteins, claudin-1, -3 and -5 , are a major constituents of BNI tight junction strands [134] and are thought to determine pore-mediated ion conductance, while size-selective diffusion is suggested to result from dynamic rearrangement of the network of junctional strands [164]. Occludin, another tetraspan transmembrane protein associated with the strands, is implicated in the regulation of paracellular movement of small hydrophilic molecules and the migration of neutrophils [4], as well as regulation of MAPkinase-dependent signaling pathways and RhoA signaling [9]. Adhesion of leukocytes to endothelia and their subsequent paracellular movement is regulated by single-span transmembrane JAMs [181]. The cytoplasmic plaque subjacent to junctional strands contains a complex of adaptor proteins, such as ZO-1, ZO-2, and ZO-3, and scaffolding proteins that are involved in cross linking and connecting junctional membrane proteins to the actin-myosin cytoskeleton, as well as recruiting a number of signaling molecules to the tight junction, including various protein kinases, protein and lipid phosphatases, $\mathrm{G}$ proteins and their regulators, and GTPases [9, 172].

The configuration of endothelia, perineurial cells and associated tight junctions that constitute the BNI confer the possibility for movement of fluid, various-sized solutes and cells across this interface in response to adaptive alterations of permeability during development or in response to trauma, disease or toxic insult. Large molecules can be moved transcellularly via pinocytotic shuttling [47, 158, 159], with modification via diabetes-induced nonenzymatic glycosylation enhancing the rate of movement into the endoneurium [117]. Paracellular ion-selectivity is conferred through claudin-1 and -3 pores in tight junction strands in the perineurium and claudin-5 pores in endoneurial endothelium [134], while reshaping the strand network is suggested to provide a pathway for the diffusion of small solutes [164], which might be the basis for endoneurial accumulation of electrolytes and increased BNI permeability to small nonelectrolytes observed in some models of experimental diabetes [84, 87, 90, 91, 136, 177]. Stimulation of regulatory pathways involving Rho-ROCK and MLCK signaling promote actin dynamics and associated myosin II activity, which can transiently dissociate endothelial tight junctions promoting the leukocyte infiltration [164] that precedes and precipitates the selflimiting, immune-mediated demyelination in EAN [131] or the movement of macrophage precursors into the endoneurium during Wallerian degeneration [165]. Clearly, an improved understanding of the dynamic nature of BNI tight junctions is essential for appreciating and further defining the homeostatic capacity of the nerve microenvironment.

\section{Conclusions}

$\mathrm{BNI}$ is preferable to BNB because the former term encompasses the regulatory nature as well as the passive barrier properties of the perineurium and endoneurial vasculature. Blood-nerve exchange and convective endoneurial fluid flow driven by a proximo-distal hydrostatic pressure gradient are the major sources of input to and output from the nerve microenvironment. The independent regulation of perineurial and endothelial permeability during development and in response to trauma is consistent with the homeostatic regulation of the nerve microenvironment. The selective permeability properties of the BNI are regulated by soluble factors that induce as well as modulate tight junctions and their associated actinomyosin cytoskeleton, adaptor, scaffold and signaling molecules. As applied to the brain and with some modification, the concept of the neurovascular unit is equally relevant for nerve and likely includes the constituents of the BNI, as well as pericytes, Schwann cells, axons, macrophages and mast cells, whose 
interactions via cell-cell and cell-matrix signaling regulate the permeability of this interface. From this perspective, pathophysiological changes of the nerve microenvironment can be viewed as a consequence of altered endoneurial homeostasis. A greater knowledge of the dynamic nature of tight junctions and the factors that induce and/or modulate these key elements of the BNI will contribute to our understanding of peripheral nerve disorders as well as to the development of therapeutic strategies and paradigms for the treatment of these disorders. Lastly, a comprehensive understanding of interspecies differences in BNI structure and function will help clarify the relevance of observations derived from animal and in vitro models to human peripheral nerve disorders.

Acknowledgments Supported by NIH grants DK078373 (APM) and NS30197 (AW), NSF grant IBN9420525 (AW), the Juvenile Diabetes Research Foundation (APM) and a grant from the MedCen Foundation (AW). Daniel P. Mizisin drew Figs. 1, 2, 4.

Open Access This article is distributed under the terms of the Creative Commons Attribution Noncommercial License which permits any noncommercial use, distribution, and reproduction in any medium, provided the original author(s) and source are credited.

\section{References}

1. Abbott NJ (2000) Inflammatory mediators and modulation of blood-brain barrier permeability. Cell Mol Neurobiol 20:131-147

2. Abbott NJ (2002) Astrocyte-endothelial interactions and bloodbrain barrier permeability. J Anat 200:629-638

3. Aguayo AJ, Charron L, Bray GM (1976) Potential of Schwann cells from unmyelinated nerves to produce myelin: a quantitative ultrastructural and autoradiographic study. J Neurocytol 5:565-573

4. Aijaz S, Balda MS, Matter K (2006) Tight junctions: molecular architecture and function. Int Rev Cytol 248:261-298

5. Allt G, Lawrenson JG (2000) The blood-nerve barrier: enzymes, transporters and receptors-a comparison with the blood-brain barrier. Brain Res Bull 52:1-12

6. Arvidson B (1979) A study of the perineurial diffusion barrier of a peripheral ganglion. Acta Neuropathol 46:139-144

7. Asbury AK, Arnason BGW, Adams RD (1969) The inflammatory lesion in idiopathic polyneuritis: its role in pathogenesis. Medicine 48:173-215

8. Ask P, Levitan H, Robinson PJ, Rapoport SI (1983) Peripheral nerve as an osmometer: role of the perineurium in frog sciatic nerve. Am J Physiol 244:C75-C81

9. Balda MS, Matter K (2008) Tight junctions at a glance. J Cell Sci 121:3677-3682

10. Ballin RHM, Thomas PK (1968) Electron microscopic observations on demyelination and remyelination in allergic neuritis. I. Demyelination. J Neurol Sci 8:1-8

11. Bell MA, Wedell AGM (1984) A morphometric study of intrafascicular vessels in mammalian sciatic nerve. Muscle Nerve 7:524-534

12. Betz AL, Firth JA, Goldstein GW (1980) Polarity of the bloodbrain barrier: distribution of enzymes between the luminal and antiluminal membranes of brain capillary endothelial cells. Brain Res 193:17-28

13. Boddingius J (1984) Ultrastructural and histophysiological studies on the blood-nerve barrier and perineurial barrier in leprosy neuropathy. Acta Neuropathol 64:282-296

14. Bradley WG, Asbury AK (1970) Duration of synthesis phase in neurilemmal cells in mouse sciatic nerve during degeneration. Exp Neurol 26:275-282

15. Brown WF, Feasby TE (1984) Conduction block and denervation in Guillain-Barre polyneuropathy. Brain 107:219-239

16. Brownlee M, Vlassara H, Cerami A (1986) Trapped immunoglobulins on peripheral nerve myelin from patients with diabetes mellitus. Diabetes 35:999-1003

17. Bundgaard M, Frokjaer-Jensen J (1982) Functional aspects of the ultrastructure of terminal blood vessels: a quantitative study on consecutive segments of the frog mesenteric microvasculature. Microvasc Res 23:1-30

18. Bunge MB, Wood PM, Tynan LB, Bates ML, Sanes JR (1989) Perineurium originates from fibroblasts: demonstration in vitro with a retroviral marker. Science 243:229-231

19. Burkel WE (1967) The histological fine structure of perineurium. Anat Rec 158:177-190

20. Calcutt NA, Allendorfer KL, Mizisin AP et al (2003) Therapeutic efficacy of sonic hedgehog protein in experimental diabetic neuropathy. J Clin Invest 111:507-514

21. Choi YK, Kim K-W (2008) Blood-neural barrier: its diversity ad coordinated cell-to-cell communication. BMB Rep 41:345-352

22. Crone C, Levitt DG (1984) Capillary permeability to small solutes. In: Renkin EM, Michel CC (eds). Handbook of physiology. The cardiovascular system, vol 4. Microcirculation. American Physiological Society, Bethesda, pp 411-466

23. Crowley NR, Nelson SL, Weerasuriya A, Black AC (1996) Endoneurial hydrostatic pressure in rat sciatic nerve during development. Soc Neurosci Abstr 22:772

24. Dyck PJ, Karnes J, Lais A, Lofgren EP, Stevens JC (1984) Pathologic alterations of the peripheral nervous system of humans. In: Dyck PJ, Thomas PK, Lambert EH, Bunge R (eds) Peripheral neuropathy. WB Saunders, Philadelphia, pp 760-870

25. Dyck PJ, Windebank AJ, Low PA, Baumann WJ (1980) Bloodnerve barrier in rat and cellular mechanisms of lead-induced segmental demyelination. J Neuropathol Exp Neurol 139:700709

26. Eaton RP, Qualls C, Bicknell J, Sibbitt WL Jr, King MM, Griffey RH (1996) Structure-function relationships within peripheral nerves in diabetic neuropathy: the hydration hypothesis. Diabetologia 39:439-446

27. Enerback L, Olsson Y, Sourander P (1965) Mast cells in normal and sectioned peripheral nerve. Z Zellforsch 66:596-608

28. Farquhar MG, Palade GE (1963) Junctional complexes in various epithelia. J Cell Biol 17:375-412

29. Feasby TE, Gilbert JJ, Brown WF et al (1986) An acute axonal form of Guillain-Barre polyneuropathy. Brain 109:1115-1126

30. Forcier NJ, Mizisin AP, Rimmer MA, Powell HC (1991) Cellular pathology of the nerve microenvironment in galactose intoxication. J Neuropathol Exp Neurol 50:235-255

31. Fraher JP (1999) The transitional zone and CNS regeneration. J Anat 194:161-182

32. Froehner SC, Davies A, Baldwin SA, Lienhard GE (1988) The blood-nerve barrier is rich in glucose transporter. J Neurocytol $17: 173-178$

33. Gerhart DZ, Drewes LR (1990) Glucose transporters at the blood-nerve barrier are associated with perineurial cells and endoneurial microvessels. Brain Res 508:46-50

34. Goyer RA (1971) Lead toxicity: a problem of environmental pathology. Am J Pathol 64:167-182 
35. Graham AR, Johnson PC (1985) Direct immunofluorescence findings in peripheral nerve from patients with diabetic neuropathy. Ann Neurol 17:450-454

36. Griffey RH, Eaton RP, Gasparovic C, Sibbitt W (1987) Galactose neuropathy. Structural changes evaluated by nuclear magnetic resonance spectroscopy. Diabetes 36:776-778

37. Griffey RH, Eaton RP, Sibbitt WL Jr, Bicknell JM (1988) Diabetic neuropathy. Structural analysis of nerve hydration by magnetic resonance spectroscopy. JAMA 18:2872-2878

38. Griffin JW (2001) Vasculitic neuropathies. Rheum Dis Clin North Am 27:751-760

39. Grotte G (1956) Passage of dextran molecules across the bloodlymph barrier. Acta Chir Scand Suppl 211:1-84

40. Hahn AF, Feasby TE, Steele A, Lovgren DS, Berry J (1988) Demyelination and axonal regeneration in Lewis rat experimental allergic neuritis depend on myelin dosage. Lab Invest 59:115-125

41. Haller FR, Low FN (1971) The fine structure of the peripheral nerve root sheath in the subarachnoid space in the rat and other laboratory animals. Am J Anat 131:1-19

42. Haller FR, Haller C, Low FN (1972) The fine structure of cellular layers and connective tissue space at spinal nerve root attachment in the rat. Am J Anat 133:109-123

43. Hartung HP, Toyka KV (1990) T cell and macrophage activation in experimental autoimmune neuritis and Guillain-Barre syndrome. Ann Neurol 27:S57-S63

44. Hirakawa H, Okajima S, Nagaoka T, Takamatsu T, Oyamada M (2003) Loss and recovery of the blood-nerve barrier in the rat sciatic nerve after crush injury are associated with expression of intercellular junctional proteins. Exp Cell Res 284:196-210

45. Jacobs JM, Macfarlane RM, Cavanagh JB (1976) Vascular leakage in the dorsal root ganglia of the rat studied with horseradish peroxidase. J Neurol Sci 29:95-107

46. Jakobsen J (1978) Peripheral nerve in early experimental diabetes: expansion of the endoneurial space as a cause of increased water content. Diabetologia 14:113-119

47. Jakobsen J, Malmgren L, Olsson Y (1978) Permeability of the blood-brain barrier in the streptozotocin-diabetic rat. Exp Neurol 60:277-285

48. Jessen KR, Mirsky R (1999) Schwann cells and their precursors emerge as major regulators of nerve development. TINS 22:402-410

49. Jessen KR, Mirsky R, Morgan L (1987) Axonal signals regulate the differentiation of non-myelin-forming Schwann cells: an immunohistochemical study of galactocerebroside in transected and degenerating nerves. J Neurosci 7:3362-3369

50. Jiang Y, Calcutt NA, Ramos KM, Mizisin AP (2006) Novel sites of aldose reductase immunolocalization in normal and streptozotocin-diabetic rats. J Peripher Nerv Syst 11:274-285

51. Johnson PC (1983) Thickening of the human dorsal root ganglion perineurial cell basement membrane in diabetes mellitus. Muscle Nerve 6:561-565

52. Kalichman MW, Myers RR (1991) Transperineurial vessel constriction in an edematous neuropathy. J Neuropathol Exp Neurol 50:408-418

53. Kalichman MW, Powell HC, Calcutt NA, Mizisin AP (1995) Mast cell degranulation and blood-nerve barrier permeability in rat sciatic nerve after 7 days of hyperglycemia. Am J Physiol 268:H740-H748

54. Kanda T, Numata Y, Mizusawa H (2004) Chronic inflammatory demyelinating polyneuropathy: decreased claudin-5 and relocated ZO-1. J Neurol Neurosurg Psychiatry 75:765-769

55. Kandel ER, Schwartz JH, Jessell TM (2000) Principles of neural science, 4th edn. McGraw-Hill, New York

56. Karnovsky MJ (1970) Morphology of capillaries with special reference to muscle capillaries. In: Crone C, Lassen NA (eds) Capillary permeability. Munksgaard, Copenhagen, pp 341-350
57. Kido Y, Yamai I, Okamoto M, Susuki F, Tsuji A (2000) Functional clarification of MCT1-mediated transport of monocarboxylic acids at the blood-brain barrier using in vitro cultured cells and in vivo BUI studies. Pharm Res 17:55-62

58. Kihara M, Schmelzer JD, Poduslo JF, Curran GL, Nickander KK, Low PA (1991) Aminoguanidine effects on nerve blood flow, vascular permeability, electrophysiology, and oxygen free radicals. Proc Natl Acad Sci USA 88:6107-6111

59. King RHM, Llewelyn JG, Thomas PK, Gilbey SG, Watkins PJ (1989) Diabetic neuropathy: abnormalities of Schwann cell and perineurial basal laminae. Implications for diabetic vasculopathy. Neuropathol Appl Neurobiol 15:339-355

60. Krinke G, Schaumberg HH, Spencer PS, Suter J, Thomann P, Hess R (1981) Pyridoxine megavitimanosis produces degeneration of peripheral sensory neurons (sensory neuronopathy) in the dog. Neurotoxicology 2:13-24

61. Kristensson K, Olsson Y (1971) The perineurium as a diffusion barrier to protein tracers: differences between mature and immature animals. Acta Neuropathol 17:127-138

62. Krnjevic K (1954) Some observations on perfused frog sciatic nerves. J Physiol 123:338-356

63. Krnjevic K (1955) The distribution of $\mathrm{Na}$ and $\mathrm{K}$ in cat nerves. J Physiol 128:473-488

64. Lampert PW (1969) Mechanisms of demyelination in experimental allergic neuritis: electron microscopic studies. Lab Invest 20:127-138

65. Landis EM, Pappenheimer JR (1963) Exchange of substances through the capillary wall. In: Hamilton WF, Dow P (eds) Handbook of physiology, Circulation, section 2, vol II. American Physiological Society, Washington DC, pp 961-1034

66. Latker CH, Wadhwani KC, Balbo A, Rapoport SI (1991) Bloodnerve barrier in the frog during Wallerian degeneration: are axons necessary for maintenance of barrier function? J Comp Neurol 309:650-664

67. Lo EH, Broderick JP, Moskowitz MA (2004) tPA and proteolysis in the neurovascular unit. Stroke 35:354-356

68. Lok J, Gupta P, Guo S et al (2007) Cell-cell signaling in the neurovascular unit. Neurochem Res 32:2032-2045

69. Low FN (1976) The perineurium and connective tissue of peripheral nerve. In: Landon DN (ed) The peripheral nerve. Chapman and Hall, London, pp 159-187

70. Low PA (1981) In vitro study of acute elevations of endoneurial pressure in mammalian peripheral nerve sheath. Exp Neurol 74:160-169

71. Low PA (1985) Endoneurial potassium is increased and enhances spontaneous activity in regenerating mammalian nerve fibers. Implications for neuropathic positive symptoms. Muscle Nerve 8:27-33

72. Low PA, Dyck PJ (1977) Increased endoneurial fluid pressure in experimental lead neuropathy. Nature 269:427-428

73. Low PA, Dyck PJ, Schmelzer JD (1982) Chronic elevation of endoneurial fluid pressure is associated with low-grade fiber pathology. Muscle Nerve 5:162-165

74. Low PA, Marchand G, Knox F, Dyck PJ (1977) Measurement of endoneurial fluid pressure with polyethylene matrix capsule. Brain Res 122:373-377

75. Low PA, Tuck RR (1984) Effects of changes in blood pressure, respiratory acidosis and hypoxia on blood flow in the sciatic nerve of the rat. J Physiol 347:513-524

76. Lundborg G (1988) Nerve injury and repair. Churchill Livingstone, Edinburgh

77. Mackenzie ML, Ghabriel MN, Allt G (1987) The bloodnerve barrier: an in vivo lanthanum tracer study. J Anat 154:27-37

78. Madrid RE, Wisniewski HM (1977) Axonal degeneration in demyelinating disorders. J Neurocytol 6:103-117 
79. Magnani P, Cherian PV, Gould GW, Greene DA, Sima AA, Brosius FF III (1996) Glucose transporters in rat peripheral nerve: paranodal expression of GLUT1 and GLUT3. Metabolism 45:1466-1473

80. Malinovsky L (1996) Sensory nerve formations in the skin and their classification. Microsc Res Tech 34:283-301

81. McCabe JS, Low FN (1969) The subarachnoid angle: an area of transition in peripheral nerve. Anat Rec 164:15-33

82. Mellick RS, Cavanagh JB (1967) Longitudinal movement of radio-iodinated albumin within extravascular spaces of peripheral nerves following three systems of trauma. J Neurol Neurosurg Psychiatry 30:458-463

83. Meyer J, Mischeck U, Veyhl M, Henzel K, Galla H-J (1990) Blood-brain barrier characteristic enzymatic properties in cultured brain capillary endothelial cells. Brain Res 514:305309

84. Mizisin AP, Kalichman MW (1993) Permeability and surface area of the blood-nerve barrier in galactose intoxication. Brain Res 618:109-114

85. Mizisin AP, Kalichman MW, Calcutt NA, Myers RR, Powell HC (1993) Decreased endoneurial fluid electrolytes in normal rat sciatic nerve after aldose reductase inhibition. J Neurol Sci 116:67-72

86. Mizisin AP, Kalichman MW, Myers RR, Powell HC (1990) Role of the blood-nerve barrier in experimental nerve edema. Toxicol Pathol 18:170-185

87. Mizisin AP, Myers RR, Heckman HM, Powell HC (1988) Dosedependence of endoneurial fluid sodium and chloride accumulation in galactose intoxication. J Neurol Sci 86:113-124

88. Mizisin AP, Powell HC (1993) Schwann cell injury is attenuated by aldose reductase inhibition in galactose intoxication. $\mathrm{J}$ Neuropathol Exp Neurol 52:78-86

89. Mizisin AP, Powell HC (2003) Diabetic peripheral neuropathy. In: Gries FA, Cameron NE, Low PA, Ziegler D (eds) Textbook of diabetic neuropathy. Thieme, Stuttgart, pp 83-87

90. Mizisin AP, Powell HC, Myers RR (1986) Edema and increased endoneurial sodium in galactose neuropathy. Reversal with an aldose reductase inhibitor. J Neurol Sci 74:35-43

91. Mizisin AP, Powell HC, Myers RR (1986) Endoneurial sodium accumulation in galactosemic rat nerves. Muscle Nerve 9:440-444

92. Myers RR, Heckman HM, Powell HC (1983) Endoneurial fluid in hypertonic. J Neuropathol Exp Neurol 42:217-224

93. Myers RR, James HC, Powell HC (1985) Laser injury of peripheral nerve: a model for focal endoneurial damage. J Neurol Neurosurg Psychiatry 48:1265-1268

94. Myers RR, Mizisin AP, Powell HC, Lampert PW (1982) Reduced nerve blood flow in hexachlorophene neuropathy. Relationship to elevated endoneurial fluid pressure. J Neuropathol Exp Neurol 41:391-399

95. Myers RR, Murakami H, Powell HC (1986) Reduced nerve blood flow in edematous neuropathies - a biochemical mechanism. Microvasc Res 32:145-151

96. Myers RR, Powell HC (1984) Galactose neuropathy: impact of chronic endoneurial edema on nerve blood flow. Ann Neurol 16:587-594

97. Myers RR, Powell HC, Costello ML, Lampert PW, Zweifach BW (1978) Endoneurial fluid pressure: direct measurement with micropipettes. Brain Res 148:510-515

98. Myers RR, Powell HC, Heckman HM, Costello ML, Katz J (1981) Biophysical and pathological effects of cryogenic nerve lesion. Ann Neurol 10:478-485

99. Myers RR, Powell HC, Shapiro HM, Costello ML, Lampert PW (1980) Changes in endoneurial fluid pressure, permeability and peripheral nerve ultrastructure in experimental lead neuropathy. Ann Neurol 8:392-401
100. Myers RR, Rydevik BL, Heckman HM, Powell HC (1988) Proximo-distal gradient in endoneurial fluid pressure. Exp Neurol 102:368-370

101. Ohi T, Poduslo JF, Curran GL, Dyck PJ (1985) Quantitative methods for detection of blood-nerve barrier alterations in experimental animal models of neuropathy. Exp Neurol 90:365-372

102. Ohara S, Ikuta F (1985) On the occurrence of the fenestrated vessels in Wallerian degeneration of the peripheral nerve. Acta Neuropathol 68:259-262

103. Ohi T, Poduslo JF, Dyck PJ (1985) Increased endoneurial albumin in diabetic polyneuropathy. Neurology 35:1790-1791

104. Ohtsuki S, Tachikawa M, Takanaga H et al (2002) The bloodbrain carrier creatine transporter is a major pathway for supplying creatine to the brain. J Cereb Blood Flow Metab 22:1327-1335

105. Olsson Y (1966) Studies on vascular permeability in peripheral nerve. I. Distribution of circulating fluorescent serum albumin in normal, crushed and sectioned rat sciatic nerve. Acta Neuropathol 7:1-15

106. Olsson Y (1968) Topographical differences in the vascular permeability of the peripheral nervous system. Acta Neuropathol 10:26-33

107. Olsson Y (1984) Vascular permeability in the peripheral nervous system. In: Dyck PJ, Thomas PK, Lambert EH, Bunge R (eds) Peripheral neuropathy, 2nd edn. Saunders, Philadelphia, pp 579-597

108. Olsson Y (1990) Microenvironment of the peripheral nervous system under normal and pathological conditions. Critical Rev Neurobiol 5:265-311

109. Olsson Y, Kristensson K (1971) Permeability of blood vessels and connective tissue sheaths in the peripheral nervous system to exogenous proteins. Acta Neuropathol 5(Suppl 5):61-69

110. Olsson Y, Reese TS (1971) Permeability of vasa nervorum and perineurium in mouse sciatic nerve studied by fluorescence and electron microscopy. J Neuropathol Exp Neurol 30:105-119

111. Orte C, Lawrenson JG, Finn TM, Reid AR, Allt G (1999) A comparison of blood-brain barrier and blood-nerve barrier endothelial cell markers. Anat Embryol 199:509-517

112. Pappenheimer JR (1953) Passage of molecules through capillary walls. Physiol Rev 33:387-423

113. Parmantier E, Lynn B, Lawson D et al (1999) Schwann cellderived desert hedgehog controls the development of peripheral nerve sheaths. Neuron 23:713-724

114. Pellegrino RG, Politis MJ, Ritchie JM, Spencer PS (1986) Events in degenerating cat peripheral nerve: induction of Schwann cell $\mathrm{S}$ phase and its relation to nerve fiber degeneration. J Neurocytol 15:17-28

115. Peters A, Palay SL, DeF Webster H (1991) The fine structure of the nervous system. Oxford University Press, New York, pp 384-394

116. Peters T (1975) Serum albumin. In: Putnam FW (ed) The plasma proteins. Academic Press, New York, pp 131-181

117. Poduslo JF, Curran GL (1992) Increased permeability across the blood-nerve barrier of albumin glycated in vitro and in vivo from patients with diabetic polyneuropathy. Proc Natl Acad Sci USA 89:2218-2222

118. Poduslo JF, Curran GL, Dyck PJ (1988) Increase in albumin, IgG and IgM blood-nerve barrier indices in human diabetic neuropathy. Proc Natl Acad Sci USA 88:4879-4883

119. Poduslo JF, Dyck PJ, Berg CT (1985) Regulation of myelination: Schwann cell transition from a myelin-maintaining state to a quiescent state after permanent nerve transection. J Neurochem 44:388-400

120. Poduslo JF, Low PA, Nickander KK, Dyck PJ (1985) Mammalian endoneurial fluid: collection and protein analysis from normal and crushed nerves. Brain Res 332:91-102 
121. Polydefkis M, Griffin JW, McArthur J (2003) New insights into diabetic polyneuropathy. JAMA 290:1371-1376

122. Powell DW (1981) Barrier function of epithelia. Am J Physiol 241:G275-G288

123. Powell HC, Braheny SL, Myers RR, Rodriguez M, Lampert PW (1983) Early changes in experimental allergic neuritis. Lab Invest 48:332-338

124. Powell HC, Costello ML, Myers RR (1981) Galactose neuropathy. Permeability studies, mechanism of edema, and mast cell abnormalities. Acta Neuropathol 55:89-95

125. Powell HC, Garrett RS, Kador PF, Mizisin AP (1991) Finestructural localization of aldose reductase and oubain-sensitive, $\mathrm{K}^{+}$-dependent $p$-nitro-phenylphosphatase in rat peripheral nerve. Acta Neuropathol 81:529-539

126. Powell HC, Myers RR (1989) The blood-nerve barrier and the pathological significance of nerve edema. In: Neuwelt EA (ed) Implications of the blood-brain barrier and its manipulation, vol 1. Plenum Press, New York, pp 199-212

127. Powell HC, Myers RR (2004) Impact of inflammatory disease on the nerve microenvironment. J Neurol Sci 220:131-132

128. Powell HC, Myers RR, Costello ML (1980) Increased endoneurial fluid pressure following injection of histamine and compound 48/80 into rat peripheral nerves. Lab Invest 43:564-572

129. Powell HC, Myers RR, Costello ML, Lampert PW (1979) Endoneurial fluid pressure in Wallerian degeneration. Ann Neurol 5:550-557

130. Powell HC, Myers RR, Lampert PW (1982) Changes in Schwann cells and vessels in lead neuropathy. Am J Pathol 109:193-205

131. Powell HC, Myers RR, Mizisin AP, Olle T, Brostoff SW (1991) Response of the axon and barrier endothelium to experimental allergic neuritis induced by autoreactive $\mathrm{T}$ cell lines. Acta Neuropathol 82:364-377

132. Powell HC, Olee T, Brostoff SW, Mizisin AP (1991) Comparative histology of experimental allergic neuritis induced with minimum length neuritogenic peptides by adoptive transfer with sensitized cells or direct sensitization. J Neuropathol Exp Neurol 50:658-674

133. Prineas JW, Spencer PS (1975) Pathology of the nerve cell body in disorders of the peripheral nervous system. In: Dyck PJ, Thomas PK, Lambert EH (eds) Peripheral neuropathy. Saunders, Philadelphia, pp 253-295

134. Pummi KP, Heape AM, Grenman RA, Peltonen JTK, Peltonen SA (2004) Tight junction proteins ZO-1, occluding, and claudins in developing and adult human perineurium. J Histochem Cytochem 52:1037-1046

135. Rapoport SI (1976) Blood-brain barrier in physiology and medicine. Raven Press, New York

136. Rechthand E, Smith QR, Latker CH, Rapoport SI (1987) Altered blood-nerve barrier permeability to small molecules in experimental diabetes mellitus. J Neuropathol Exp Neurol 46:302-314

137. Rechthand E, Smith QR, Rapoport SI (1985) Facilitated transport of glucose from blood into peripheral nerve. J Neurochem 45:957-964

138. Rechthand E, Smith QR, Rapoport SI (1987) Transfer of nonelectrolytes from blood into peripheral nerve endoneurium. Am J Physiol 252:H1175-H1182

139. Renkin EM (1977) Multiple pathways of capillary permeability. Circ Res 41:735-743

140. Rippe B, Haraldsson B (1987) How are macromolecules transported across the capillary wall? News Physiol Sci 2:135-138

141. Ross MH, Reith EJ (1969) Perineurium: evidence for contractile elements. Science 165:604-605
142. Rossiter RJ (1961) The chemistry of Wallerian degeneration. In: Folch-Pi J (ed) Chemical pathology of the nervous system. Pergamon Press, New York, pp 207-227

143. Rubenstein A, Arbit E (1990) Spinal cord blood flow in the rat under normal physiological conditions. Neurosurgery 27:882-886

144. Rundquist I, Smith QR, Michael ME, Ask P, Oberg PA, Rapoport SI (1985) Sciatic nerve blood flow measured by laser Doppler flowmetry and $\left[{ }^{14} \mathrm{C}\right]$ iodoantipyrine. Am J Physiol 248:H311-H317

145. Said G, Slama G, Selva J (1983) Progressive centripetal degeneration of axons in small fiber type diabetic polyneuropathy. A clinical and pathological study. Brain 106:791-807

146. Saida K, Kawakami H, Ohta M, Iwamura K (1997) Coagulation and vascular abnormalities in Crow-Fukase syndrome. Muscle Nerve 20:486-492

147. Saito T, Zhang Z, Ohtsubo T et al (2001) Homozygous disruption of the mdrla p-glycoprotein gene affects blood-nerve barrier function in mice administered with neurotoxic drugs. Acta Otolaryngol 121:735-742

148. Sano Y, Shimuzu F, Nakayama H et al (2007) Endothelial cells constituting blood-nerve barrier have highly specialized characteristics as barrier-forming cells. Cell Struct Funct 32:139-147

149. Sasaki H, Schmelzer JD, Zollman PJ, Low PA (1997) Neuropathology and blood flow of nerve, spinal roots and dorsal root ganglia in longstanding diabetic rats. Acta Neuropathol 93:118-128

150. Schmelzer JD, Low PA (1988) The effects of hyperbaric oxygenation and hypoxia on the blood-nerve barrier. Brain Res 473:321-326

151. Seneviratne KN (1972) Permeability of blood-nerve barriers in the diabetic rat. J Neurol Neurosurg Psychiatry 35:156-162

152. Shanthaveerappa TS, Bourne GH (1962) The "perineurial epithelium', a metabolically active, continuous, protoplasmic cell barrier surrounding peripheral nerve fasciculi. J Anat 96:527-537

153. Shanthaveerappa TS, Bourne GH (1966) Perineurial epithelium: a new concept of its role in the integrity of the peripheral nervous system. Science 154:1464-1467

154. Sharghi-Namini S, Turmaine M, Meier C et al (2006) The structural and functional integrity of peripheral nerves depends on the glial-derived signal desert hedgehog. J Neurosci 26:6364-6376

155. Shelton KR, Egle PM (1982) The proteins of lead-induced intranuclear inclusion bodies. J Biol Chem 257:11802-11807

156. Shimizu F, Yasuteru S, Masa-aki A et al (2010) Peripheral nerve pericytes modify the blood-nerve barrier function and tight junctional molecules through the secretion of various soluble factors. J Cell Physiol. doi:10.1002/jcp.22337

157. Shinowara NL, Michel ME, Rapoport SI (1982) Morphological correlates of permeability in the frog perineurium: vesicles and transcellular channels. Cell Tissue Res 227:11-22

158. Sima AAF, Hay K (1981) Functional aspects and pathogenetic considerations of the neuropathy in the spontaneously diabetic BB-Wistar rat. Neuropathol Appl Neurobiol 7:341-350

159. Sima AAF, Robertson DM (1978) The perineurial and bloodnerve barriers in experimental diabetes. Acta Neuropathol 44:189-195

160. Smith CE, Atchabahian A, Mackinnon SE, Hunter DA (2001) Development of the blood-nerve barrier in neonatal rats. Microsurgery 21:290-297

161. Smith ME, Jones TA, Hilton D (1998) Vascular endothelial cadherin is expressed by perineurial cells of peripheral nerve. Histopathology 32:411-413 
162. Soderfeldt B (1974) The perineurium as a diffusion barrier to protein tracers. Influence of histamine, serotonine and bradykinine. Acta Neuropathol 27:55-60

163. Spencer PS, Weinberg HJ, Raines CS (1975) The perineurial window-a new model of focal demyelination and remyelination. Brain Res 96:323-329

164. Steed E, Balda MS, Matter K (2009) Dynamics and functions of tight junctions. TICB. doi:10.1016/j.tcb.2009.12.002

165. Stoll G, Griffin JW, Li CY, Trapp BD (1989) Wallerian degeneration in the peripheral nervous system: participation of both Schwann cells and macrophages in myelin degradation. J Neurocytol 18:671-683

166. Stoll G, Jander S, Myers RR (2002) Degeneration and regeneration in the peripheral nervous system: from August Waller's observation on neuroinflammation. J Peripher Nerv Syst 7:13-27

167. Stoll G, Trapp BD, Griffin JW (1989) Macrophage function during Wallerian degeneration of rat optic nerve: clearance of degenerating myelin and Ia expression. J Neurosci 9:2327-2335

168. Sunderland S (1946) The effect of rupture of the perineurium on the contained nerve fibres. Brain 69:149-152

169. Sunderland S (1978) Nerves and nerve injury. Churchill Livingstone, Edinburgh

170. Tamara A, Asano T, Sano K (1978) Measurement of spinal cord blood flow in rabbits: central gray matter flow and $\mathrm{CO}_{2}$ reactivity. No To Shinkei 30:383-386

171. Taylor AE, Granger DN (1984) Exchange of macromolecules across the microcirculation. In: Renkin EM, Michel CC (eds). Handbook of physiology, section 2, The cardiovascular system, vol 4, Microcirculation. American Physiological Society, Bethesda, pp 467-520

172. Terry S, Nie M, Matter K, Balda MS (2010) Rho signaling and tight junction functions. Physiology 25:16-26

173. Thomas PK, Bhagat S (1978) The effect of extraction of the intrafascicular contents of peripheral nerve trunks on perineurial structure. Acta Neuropathol 43:135-141

174. Tsao JW, George EB, Griffin JW (1999) Temperature modulation reveals three distinct stages of Wallerian degeneration. J Neurosci 19:4718-4726

175. Tserentsoodol N, Shin BC, Koyama H, Suzuki T, Takata K (1999) Immunolocalization of tight junction proteins, occludin and ZO-1, and GLUT1 in the cells of the blood-nerve barrier. Arch Histol Cytol 62:459-469

176. Vorbrodt AW, Dobrogowska DH, Lossinsky AS (1994) Ultracytochemical studies of the effects of aluminum on the bloodbrain barrier of mice. J Histochem Cytochem 42:203-212

177. Wadhwani KC, Casper-Velu LE, Murphy VA, Smith QR, Kador PF, Rapoport SI (1989) Prevention of nerve edema and increased blood-nerve barrier permeability-surface area product in galactosemic rats by aldose reductase or thromboxane synthesis inhibitors. Diabetes 38:1469-1477

178. Wadhwani KC, Koistinaho J, Balbo A, Rapoport SI (1991) Blood-nerve and blood-brain barrier permeabilities and nerve vascular space in Fischer-344 rats of different ages. Mech Ageing Dev 58:177-190

179. Wadhwani KC, Latker CH, Balbo A, Rapoport SI (1989) Perineurial permeability and endoneurial edema during Wallerian degeneration of the frog peripheral nerve. Brain Res 493:231-239

180. Waxman BH, Adams RD (1955) Allergic neuritis: experimental disease of rabbits induced by the injection of peripheral nervous tissue and adjuvants. J Exp Med 102:213-236

181. Weber C, Fraemohs L, Dejana E (2007) The role of junctional adhesion molecules in vascular inflammation. Nat Rev Immunol 7:467-477
182. Weerasuriya A (1987) Permeability of endoneurial capillaries to $\mathrm{K}, \mathrm{Na}$, and $\mathrm{Cl}$ and its relation to peripheral nerve excitability. Brain Res 419:188-196

183. Weerasuriya A (1988) Patterns of change in endoneurial capillary permeability and vascular space during Wallerian degeneration. Brain Res 445:181-187

184. Weerasuriya A (1990) Permeabilities of endoneurial capillaries and perineurium of rat sciatic nerve to ${ }^{22} \mathrm{Na}$ during development. Physiologist 33:A-100

185. Weerasuriya A (1993) Changes in the permeability coefficient surface area product (PS) of the blood-nerve interface (BNI) to sodium in degenerating and regenerating rat sciatic nerve. 11th Biennial Meeting of the Peripheral Nerve Study Group, Aachen, Germany

186. Weerasuriya A (2005) Blood-nerve interface and endoneurial homeostasis. In: Dyck PJ, Thomas PK (eds) Peripheral neuropathy, 4th edn. Elsevier, New York, pp 651-665

187. Weerasuriya A, Coath G, Crowley N (1996) Endoneurial Na concentration and hydrostatic pressure in galactose neuropathy. FASEB J 10:A764

188. Weerasuriya A, Curran GL, Poduslo JF (1989) Blood-nerve transfer of albumin and its implications for the endoneurial microenvironment. Brain Res 494:114-121

189. Weerasuriya A, Curran GL, Poduslo JF (1990) Developmental changes in blood-nerve transfer of albumin and endoneurial albumin content in rat sciatic nerve. Brain Res 521:40-46

190. Weerasuriya A, Curran GL, Poduslo JF (1990) Physiological changes in the sciatic nerve endoneurium of lead intoxicated rats: a model of endoneurial homeostasis. Brain Res 517:1-6

191. Weerasuriya A, Hockman CH (1992) Perineurial permeability to sodium during Wallerian degeneration in rat sciatic nerve. Brain Res 581:327-333

192. Weerasuriya A, Nelson SL, Crowley NR (1998) Evidence for endoneurial fluid flow from endoneurial hydrostatic pressure measurements in transected and crushed rat sciatic nerves. Soc Neurosci Abstr 24:267

193. Weerasuriya A, Rapoport SI (1986) Endoneurial capillary permeability to $\left[{ }^{14} \mathrm{C}\right]$ sucrose in frog sciatic nerve. Brain Res 375:150-156

194. Weerasuriya A, Rapoport SI, Taylor RE (1979) Modification of permeability of frog perineurium to $\left[{ }^{14} \mathrm{C}\right]$ sucrose by stretch and hypertonicity. Brain Res 173:503-512

195. Weerasuriya A, Rapoport SI, Taylor RE (1980) Ionic permeabilities of the frog perineurium. Brain Res 191:405-415

196. Weerasuriya A, Rapoport SI, Taylor RE (1980) Perineurial permeability increases during Wallerian degeneration. Brain Res 192:581-585

197. Weiss P, Wang H, Taylor AC, Edds MV (1945) Proximo-distal fluid convection in the endoneurial spaces of peripheral nerves, demonstrated by colored and radioactive (isotope) tracers. Am J Physiol 143:521-540

198. Williams PL, Hall SM (1971) Chronic Wallerian degeneration-an in vivo and ultrastructural study. J Anat 109:487-503

199. Willison HJ (2005) The immunobiology of Guillain-Barre syndromes. J Peripher Nerv Syst 10:94-112

200. Windebank AJ, Dyck PJ (1984) Lead intoxication as a model of primary segmental demyelination. In: Dyck PJ, Thomas PK, Lambert EH, Bunge R (eds) Peripheral neuropathy, 2nd edn. Saunders, Philadelphia, pp 650-665

201. Windebank AJ, McCall JT, Hunder HG, Dyck PJ (1980) The endoneurial content of lead related to the onset and severity of segmental demyelination. J Neuropathol Exp Neurol 39:692-699

202. Wisniewski H, Terry RD, Whitaker JN, Cook SD, Dowling PC (1969) Landry-Guillain-Barre syndrome. A primary demyelinating disease. Arch Neurol 21:269-276 
203. Zhou L, Griffin JW (2003) Demyelinating polyneuropathies. Curr Opin Neurol 16:307-313

204. Yousef N, Xia RH, Ubogu EE (2010) Development and characterization of a novel human in vitro blood-nerve barrier model using primary endoneurial endothelial cells. J Neuropathol Exp Neurol 69:82-97

205. Zochodne DW (2002) Nerve and ganglion blood flow: an appraisal. Int Rev Neurobiol 50:161-202 